\title{
AdRIAAN VAN ROOMEN E SUA CORRESPONDÊNCIA: DESAFIOS E CONTROVÉRSIAS MATEMÁTICAS NO SÉCULO XVI
}

\author{
Zaqueu Vieira Oliveira \\ Universidade de São Paulo - USP - Brasil \\ Thomás A. S. Haddad \\ Universidade de São Paulo - USP - Brasil
}

(aceito para publicação em maio de 2018)

\begin{abstract}
Resumo
A correspondência foi um dos meios de comunicação mais utilizados por cientístas e estudiosos durante o renascimento. Além de encontrarmos evidências dos interesses científicos e matemáticos de cada autor, são nessas cartas que encontramos também evidências das práticas consideradas válidas dentro do ambiente científico e matemático daquele tempo. Em um trabalho recente, Catherine Goldstein (2013) considera a rede de correspondentes de Marin Mersenne (1588-1648) como uma instituição, termo utilizado para mostrar as relações entre os interlocutores, as práticas consideradas válidas e as polêmicas e as discórdias sobre os modos de se resolver problemas matemáticos, fatos evidenciados nas cartas. Neste artigo, apresentamos a tradução de quatro cartas de Adriaan van Roomen (1561-1615) e um ensaio sobre duas controvérsias em que o autor figura como um dos protagonistas: o debate entre van Roomen e François Viète (1540-1603) e os desafios trocados por eles em suas obras publicadas no final do século XVI e a batalha de Joseph Justus Scaliger (1540-1609) tentando se defender de um grupo de matemáticos, que inclui van Roomen, que refutaram os erros na sua solução para o clássico problema da quadratura do círculo. Apontaremos como estas e outras questões que aparecem na Correspondência de van Roomen nos demonstrando como se dava a prática matemática no século XVI e como podemos considerá-la como uma instituição, no sentido exposto por Goldstein.
\end{abstract}

Palavras-chave: Matemática, História, Correspondência, Controvérsias. 


\title{
[ADRIAAN VAN ROOMEN AND HIS CORRESPONDENCE: MATHEMATICAL CHALLENGES AND DISPUTES IN THE $16^{\mathrm{TH}}$ CENTURY]
}

\begin{abstract}
Correspondence was one of the most widely used means of communication by scholars and scholars during the Renaissance. In addition to finding evidence of the scientific and mathematical interests of each author, there is in these letters evidence of practices considered valid within the scientific and mathematical environment of that time. In a recent work, Catherine Goldstein (2013) considers Marin Mersenne's network of correspondents (1588-1648) as an institution, a term used in the sense that the letters show us the relations between the interlocutors, the practices considered valid and the controversies and the discord over ways of solving mathematical problems. In this paper, we present the translation of four letters by Adriaan van Roomen (1561-1615) and an essay on two controversies in which the author figures as one of the protagonists: the debate between van Roomen and François Viète (1540-1603) and the challenges exchanged for them in their works published in the late sixteenth century and the battle of Joseph Justus Scaliger (1540-1609) trying to defend himself against a group of mathematicians, including van Roomen, who refuted the errors in his solution to the classic problem of square of the circle. We will point out how these and other questions that appear in the Correspondence of van Roomen show us how the mathematical practice was given in the sixteenth century and how we can consider it as an institution, in the sense exposed by Goldstein.
\end{abstract}

Keywords: Mathematics, History, Correspondence, Disputes.

\section{Introdução}

No campo da Sociologia da Ciência, há um intenso debate que busca descrever a estrutura da atividade científica como instituição social. Sobre este assunto, sociólogos como Robert King Merton e Bruno Latour trazem grandes contribuições em seus trabalhos. Ainda nesta linha de pensamento, outro trabalho relevante é o de Catherine Goldstein que nos traz apontamentos de como a rede de correspondentes de Marin Mersenne (1588-1648) pode ser considerada como uma instituição. No entendimento da autora, mesmo que uma correspondência não esteja ligada a um lugar específico, que não tenha tido qualquer tipo de reconhecimento oficial ou não continha regras explícitas de funcionamento, ainda assim, as polêmicas e as discórdias sobre os modos de se resolver problemas matemáticos e os desafios à inteligência dos interlocutores podem ser justificativas para classificar este meio de produção científica como uma instituição.

A correspondência, no Renascimento, foi um dos meios mais utilizados para o intercâmbio de informações entre os estudiosos. Adriaan van Roomen (1561-1615) foi um 
desses homens e sua atividade epistolar esteve a serviço tanto de questões ligadas ao desenvolvimento matemático (e também científico) como aos assuntos cotidianos e religiosos de seu interesse. Tais cartas são uma rica fonte de informações e aqui apresentaremos um estudo inicial de como sua rede de correspondentes também pode ser considerada como instituição no sentido atribuido por Goldstein.

Dentre os diversos assuntos abordados, a Correspondência de van Roomen, escrita no final do século XVI, mostra alguns aspectos de como se deu a polêmica sobre o clássico problema matemático grego da quadratura do círculo e a resolução dada pelo humansita Joseph Justus Scaliger (1540-1609). Outro fato mencionado é a troca de desafios matemáticos entre van Roomen e o matemático francês François Viète (1540-1603) e que deram origem a algumas publicações para ambos os autores.

Neste artigo temos como objetivo apresentar a tradução para o português de quatro cartas de van Roomen e um breve estudo sobre como podemos compreender as controvérsias e desafios estabelecidos entre matemáticos do século XVI como uma instituição.

\section{Desafios e controvérsias nas ciências e na matemática}

Naquela que ainda é uma das mais influentes tentativas de descrever a estrutura da moderna atividade científica como instituição social (descrição que é, ao mesmo tempo, prescrição para o seu "bom funcionamento") o sociólogo norte-americano Robert King Merton apresentou, em 1942, quatro normas que seriam constitutivas do etos da ciência: universalismo, comunalismo, desinteresse, e ceticismo organizado. O primeiro, para Merton, dizia respeito ao "imperativo funcional" do "livre acesso à empreitada científica", a despeito de qualquer característica pessoal ou social dos seus praticantes, tais como gênero, nacionalidade, religião, classe - exceto sua competência. O comunalismo, por sua vez, seria a incompatibilidade de toda forma de propriedade intelectual com os objetivos da ciência, e a necessidade de compartilhamento imediato e livre de qualquer remuneração (exceto o "reconhecimento pelos pares") de descobertas e resultados. Diretamente ligado a essa norma, o desinteresse exigiria a limitação absoluta da motivação dos pesquisadores ao avanço da própria ciência, sem espaço para qualquer benefício ou vaidade pessoais como propulsores de sua atividade. Finalmente, o ceticismo organizado seria a obrigação de duvidar honestamente de qualquer resultado, sem importar quem o descobriu ou anunciou em outras palavras, não caberia a um cientista aceitar cegamente as afirmações de um, e desconfiar imediatamente das de outro, um estado de coisas que trairia a própria norma do universalismo (MERTON, 1973).

Apesar de essas normas parecerem representar um ideal excessivamente positivo, ou mesmo "irênico", da atividade científica, Merton não comete a ingenuidade de localizálas em nenhum tipo de moral superior da qual os praticantes individuais da pesquisa seriam dotados. Antes, a aplicação das normas decorreria de mecanismos institucionais poderosos de controle dos seus comportamentos, recompensando a conformidade e punindo o desvio. Historicamente, instituições com essa capacidade só teriam surgido em meados do século XVII, particularmente a academia científica da Inglaterra (a da França, que poderia ser outro exemplo importante, nem desperta o interesse do sociólogo). Na interpretação de 
Merton, esta seria, a rigor, a primeira instituição de fato a organizar um campo de atividades até então "anárquico", dominado por lógicas de comportamento ultralocais ou mesmo individuais.

Duas frentes de crítica à descrição/prescrição de Merton, entre outras possíveis, serão de especial importância para nossos propósitos neste trabalho. A primeira, que começou a ganhar força ainda na década de 1970, refere-se ao reconhecimento da importância fundamental das controvérsias na ciência. Longe de serem desvios das normas mertonianas de funcionamento normal da pesquisa, as controvérsias, com tudo o que carregam de manobras desleais, campanhas de difamação de adversários, limitação de acesso desimpedido a resultados e recursos, e imensos interesses pessoais nelas investidos, têm sido reconhecidas como elementos estruturantes da atividade científica. No extremo, conforme Bruno Latour, um dos autores a quem mais se deve o estatuto central adquirido pelo estudo das controvérsias na prática da história e da sociologia das ciências, o próprio resultado de uma disputa científica é que determinaria que algo seja considerado como parte da "realidade objetiva" - e esse resultado seria, por sua vez, determinado justamente não pela "verdade dos fatos" (porque ausente), mas pelos recursos mais eficazmente mobilizados pelo partido vencedor, sobretudo recursos sociais, financeiros, retóricos etc. (LATOUR; WOOLGAR, 1997).

A outra linha de refutação do esquema de Merton, muito menos explorada, referese a um questionamento da sua periodização. Não será possível que antes da fundação da Royal Society de Londres ou da Académie des Sciences de Paris possamos localizar lógicas institucionais organizando o funcionamento de algum campo da pesquisa? Cabe o esclarecimento, neste ponto, de que por "instituição" não precisamos entender unicamente uma "organização" explícita, sede, regras escritas de admissão e funcionamento, reconhecimento por autoridades políticas etc. Como as ciências sociais há muito tempo reconhecem, uma instituição pode perfeitamente operar, e na verdade é frequente que o faça, de maneira difusa, através de regras implícitas de reconhecimento e comportamento dos seus participantes. Em outras palavras, a maior parte das instituições sociais não se apresenta na forma de organizações com fronteiras claras, como uma academia científica, uma universidade, um exército, mas sim como entidades pertencentes, talvez possamos dizer assim, ao domínio da cultura e do simbólico.

Em um trabalho altamente original, e ainda isolado, a historiadora da matemática Catherine Goldstein sugeriu precisamente que a rede de correspondentes de Marin Mersenne, na década de 1630, seja tomada como uma verdadeira instituição. Ainda que por sua própria natureza, obviamente, essa rede jamais tenha funcionado em um lugar específico, que não tenha tido qualquer reconhecimento oficial, ou regras explícitas de funcionamento, mesmo assim ela incorporou algumas dezenas de matemáticos europeus, produziu diferenciações internas no grupo (parcialmente subsidiárias de suas posições sociais "externas", mas também parcialmente autônomas), recompensou ou puniu determinados comportamentos, e determinou formas de produção e transmissão do conhecimento matemático. Crucialmente para nós, essas formas de produção e transmissão, detalhadamente analisadas por Goldstein, não corresponderam às normas mertonianas, ainda que nada impedisse a instituição, a princípio, de rumar tendencialmente em sua direção. Ou melhor, talvez houvesse um impedimento, que é justamente aquele desnudado 
pelos estudos de controvérsias: a rede de correspondências de Mersenne, antes de suprimir as disputas, promoveu-as rotineiramente. Polêmicas amargas, insultos velados ou até abertos, discórdia permanente sobre a maneira correta de resolver problemas matemáticos, desafios à inteligência dos interlocutores, contradesafios, tréplicas (com Mersenne funcionando como intermediário ou "centro de distribuição")... - é disso que se trata essa correspondência matemática que a historiadora acertadamente classifica como uma instituição (GOLDSTEIN, 2013).

"A correspondência de Mersenne, como uma instituição matemática, cumpriu seu objetivo principal: socializar em conjunto pessoas interessadas em vários graus pela matemática, mas provenientes de círculos sociais e origens científicas extremamente diferentes. A matemática foi usada como um elo social, é claro, mas o modelo não é de separação estrita de papéis e tarefas. $O$ acordo veio em primeiro lugar sobre uma organização amplamente compartilhada da prática matemática - ou até mais, de sua imagem: soluções efetivas (interpretadas como práticas) e regras de conduta estavam ambas no topo das prioridades, em uma configuração que lembra os ideais baconianos. Testar métodos - e ainda mais o próprio método - nas condições de confiança restrita que permeiam a rede necessária para a solução de problemas, que por sua vez eram a fonte de avaliação para quaisquer resultados matemáticos" (GOLDSTEIN, 2013, p. 273, tradução nossa).

Utilizando os termos de Thomas Kuhn, a autora afirma que "as controvérsias são usualmente associadas a perturbações ou mundaças de paradigmas, e raramente são integradas na ordem social da chamada ciência normal". Ao apresentar a Correspondência de Mersenne como instituição, Goldstein (2013) coloca as controvérsias como parte fundamental para que essa segunda ideia possa ser solidificada.

A partir dessa importante fundação assentada por Goldstein é que propomos pensar na própria cultura escrita em que vivem os matemáticos europeus dos séculos XVI e XVII como uma instituição que merece ser investigada em outros aspectos. Se o seu brilhante estudo de caso revela a prática endêmica da matemática como disputa, desafio e controvérsia no domínio da cultura escrita que é representado pela rede epistolar de Mersenne, sugerimos que a parcela dessa mesma cultura representada pela palavra (e a "linguagem matemática") impressa também nos leva à mesma conclusão: uma prática institucionalizada dominada pelo desafio, pela provocação, pelo ataque e contra-ataque.

É este ponto que buscamos discutir através de algumas cartas do matemático belga Adriaan van Roomen. Antes, porém, apresentamos alguns detalhes sobre as cartas ainda existentes, pois muitas se perderam ao longo da história. Cabe mencionar ainda que o estudo aqui apresentado faz uma análise mais ampla se utilizando de outras cartas e também de obras dos estudiosos mencionados na introdução deste artigo. 


\section{A correspondência de van Roomen}

Para se informar acerca de assuntos científicos e de outras temáticas de seu interesse, van Roomen utilizou-se de cartas como meio de comunicação. A Correspondência de Adriaan van Roomen foi editada pelo historiador Paul Bockstaele nos volumes 3 e 19 do periódico LIAS - Sources and Documents Relating to the Early Modern History of the Ideas (BOCKSTAELE, 1976; BOCKSTAELE, 1992) totalizando 47 cartas, conforme descrito na tabela abaixo.

\begin{tabular}{|c|c|c|c|c|c|}
\hline $\mathbf{N}^{\mathbf{o}}$ & Remetente/Cidad & de origem & Destinatário/Cidade de d & estino & Data \\
\hline 1 & Van Roomen & Louvain & Clavius & Roma & $11 / 05 / 1592$ \\
\hline 2 & Van Roomen & Louvain & Clavius & Roma & $12 / 09 / 1592$ \\
\hline 3 & Van Roomen & Louvain & Jan Moretus & Antuérpia & 07 e $10 / 01 / 1593$ \\
\hline 4 & Jan Moretus & Antuérpia & Van Roomen & Louvain & $13 / 01 / 1593$ \\
\hline 5 & Van Roomen & Louvain & Clavius & Roma & $17 / 03 / 1593$ \\
\hline 6 & Van Roomen & Wurceburgo & Clavius & Roma & $30 / 06 / 1593$ \\
\hline 7 & Van Roomen & Wurceburgo & Clavius & Roma & $20 / 09 / 1593$ \\
\hline 8 & Van Roomen & Wurceburgo & Clavius & Roma & $11 / 11 / 1593$ \\
\hline 9 & Justus Lipsius & Louvain & Van Roomen & Wurceburgo & $21 / 11 / 1593$ \\
\hline 10 & Van Roomen & Wurceburgo & $\begin{array}{l}\text { Julius Echter (Príncipe- } \\
\text { Bispo de Wurceburgo) }\end{array}$ & Wurceburgo & $01 / 01 / 1594$ \\
\hline $10 a$ & Van Roomen & Frankfurt & J.J. Scaliger & Leiden & $04 / 10 / 1594$ \\
\hline 11 & Van Roomen & Wurceburgo & Clavius & Roma & $20 / 11 / 1594$ \\
\hline 12 & Van Roomen & Wurceburgo & Ulisse Aldrovandi & Bologna & $\begin{array}{l}\text { Entre ??/07/1594 } \\
? ? / 06 / 1595\end{array}$ \\
\hline 13 & Van Roomen & Wurceburgo & Justus Lipsius & Louvain & $08 / 02 / 1595$ \\
\hline 14 & J.J. Scaliger & Leiden & Van Roomen & Wurceburgo & $31 / 03 / 1595$ \\
\hline 15 & Van Roomen & Wurceburgo & Clavius & Roma & $03 / 10 / 1595$ \\
\hline 16 & Van Roomen & Wurceburgo & Joannes Moretus & Antuérpia & $24 / 10 / 1595$ \\
\hline 17 & Van Roomen & Wurceburgo & Joannes Moretus & Antuérpia & $23 / 11 / 1595$ \\
\hline 18 & Van Roomen & Wurceburgo & Clavius & Roma & $01 / 07 / 1597$ \\
\hline 19 & Van Roomen & Wurceburgo & Clavius & Roma & $17 / 09 / 1597$ \\
\hline 20 & Van Roomen & Wurceburgo & Grienberger & Roma & $10 / 02 / 1598$ \\
\hline 21 & Van Roomen & Wurceburgo & Clavius & Roma & $10 / 02 / 1598$ \\
\hline $21 \mathrm{a}$ & Van Roomen & Wurceburgo & $\begin{array}{l}\text { J. G. Herwart von } \\
\text { Hohenburg }\end{array}$ & Munique & $01 / 07 / 1598$ \\
\hline $21 b$ & $\begin{array}{l}\text { J. G. Herwart von } \\
\text { Hohenburg }\end{array}$ & & Van Roomen & & ??/??/1598 \\
\hline $21 c$ & Van Roomen & & $\begin{array}{l}\text { J.G. Herwart } \\
\text { Hohenburg }\end{array}$ & Munique & ??/??/1598 \\
\hline 22 & Van Roomen & Wurceburgo & Clavius & Roma & $15 / 10 / 1598$ \\
\hline 23 & Van Roomen & Wurceburgo & Grienberger & Roma & $15 / 10 / 1598$ \\
\hline 24 & Van Roomen & & Clavius & Roma & \\
\hline 25 & Van Roomen & Frankfurt & Clavius & Roma & $? ? / 04 / 1601$ \\
\hline 26 & Van Roomen & Wurceburgo & Joannes Faber & Roma & $25 / 10 / 1601$ \\
\hline 27 & Van Roomen & Wurceburgo & Clavius & Roma & $25 / 10 / 1601$ \\
\hline 28 & Van Roomen & Wurceburgo & Clavius & Roma & $01 / 11 / 1601$ \\
\hline $28 \mathrm{a}$ & Wendelinus Jung & & Van Roomen & & $14 / 01 / 1602$ \\
\hline 29 & Van Roomen & Frankfurt & Clavius & Roma & $10 / 04 / 1602$ \\
\hline 30 & Van Roomen & Frankfurt & G. A. Magini & Bologna & $10 / 04 / 1602$ \\
\hline 31 & Van Roomen & Frankfurt & G. A. Magini & Bologna & $26 / 09 / 1602$ \\
\hline
\end{tabular}




\begin{tabular}{|c|c|c|c|c|c|}
\hline 32 & Van Roomen & Frankfurt & Clavius & Roma & $26 / 09 / 1602$ \\
\hline 33 & G. A. Magini & Bologna & Van Roomen & Wurceburgo & $10 / 03 / 1603$ \\
\hline 34 & Van Roomen & Wurceburgo & $\begin{array}{l}\text { Julius Echter (Príncipe- } \\
\text { Bispo de Wurceburgo) }\end{array}$ & Wurceburgo & $19 / 03 / 1603$ \\
\hline 35 & Van Roomen & Louvain & Clavius & Roma & $28 / 12 / 1604$ \\
\hline 36 & Van Roomen & Frankfurt & G. A. Magini & Bologna & $? ? / 09 / 1595$ \\
\hline 37 & Van Roomen & Louvain & Kepler & Prague & $13 / 05 / 1609$ \\
\hline 38 & Van Roomen & Prague & Kepler & Prague & Entre 1600 e 1612 \\
\hline 39 & J. Brozek & Cracóvia & Van Roomen & Zamosc & $01 / 10 / 1610$ \\
\hline 40 & Van Roomen & Zamosc & J. Brozek & Cracóvia & $05 / 02 / 1611$ \\
\hline 41 & J. Brozek & Cracóvia & Van Roomen & Zamosc & $? ? / 01 / 1612$ \\
\hline 42 & Van Roomen & Wurceburgo & Johann Hartmann Beyer & Frankfurt & $24 / 03 / 1615$ \\
\hline
\end{tabular}

Tabela 1: A Correspondência de Adriaan van Roomen editada por Bockstaele $(1976 ; 1992)$. O número das cartas é o mesmo utilizado pelo editor. Em itálico, cartas cuja tradução é apresentada neste artigo.

As cartas editadas são apresentadas por Bockstaele (1976; 1992) em latim, acrescidas de notas explicativas sobre os conteúdos e assuntos abordados, além da indicação da biblioteca e localização de cada carta.

Como é possível observar, do conjunto de cartas ainda existentes, dezenove foram enviadas para Christoph Clavius (1538-1612), provavelmente o maior correspondente de van Roomen. Entretanto, todas foram enviadas por van Roomen, não restando nenhuma resposta de Clavius. Sobre o que eles conversavam? De acordo com a carta [1], de 11 de maio de 1592, Clavius e van Roomen se conheceram em 1585 em uma viagem que van Roomen fez a Roma e, dentre os assuntos que conversaram naquele momento, trataram de aritmética e álgebra. Depois disto, van Roomen voltou a se comunicar com Clavius através do envio de cartas de 1592 até 1604, sempre abordando temáticas relacionadas à matemática.

Dentre os assuntos tratados nas cartas entre van Roomen e Clavius, os mais recorrentes são: a construção de tabelas trigonométricas, a resolução de problemas geométricos gregos, como a quadratura do círculo e o problema de Apolônio e questões que remetem às práticas científicas em voga, como o acompanhamento das atividades de outros matemáticos, as dificuldades encontradas para escrita e publicação de obras, a influencia de aspectos religiosos na produção científica e as viagens para as feiras de livros.

Outro correspondente de van Roomen que nos interessa neste artigo é Scaliger. Na Correspondência ainda existente, encontramos duas cartas, uma enviada por van Roomen a Scaliger em 1594 e sua resposta, de 1595. Ambas as cartas tratam, dentre outros assuntos, da polêmica sobre a solução encontrada por Scaliger para a quadratura do círculo.

Ademais, outro importante correspondente de van Roomen foi Viète, porém, nenhuma carta sobreviveu (BOCKSTAELE, 1976).

Em um projeto de pesquisa desenvolvidos por nós, foi realizada a tradução de oito cartas envidas por van Roomen a Clavius na virada do século XVI para o XVII, especificamente entre 1597 e 1601 . Como as cartas apresentavam fatos relacionados às cartas trocadas entre van Roomen e Scaliger, também as traduzimos no âmbito do referido projeto, cujo principal objetivo foi discutir aspectos relacionados à prática matemática daquele período. 
Neste artigo, selecionamos quatro destas cartas para apresentar uma tradução para o português: as duas primeiras - [10a] de 1594 e [14] de 1595 - foram trocadas entre o matemático belga e Scaliger e as duas seguintes - [18] e [19] - foram enviadas por van Roomen a Clavius no ano de 1597. A tradução da carta [18] já foi apresentada em um trabalho anterior (GONÇALVES; OLIVEIRA, 2007), porém, as outras três são inéditas em nosso idioma.

\section{Os desafios matemáticos entre van Roomen e Viète}

O primeiro dos trabalhos de van Roomen que merece nossa atenção é a Ideae mathematicae pars prima de 1593 . A obra trata principalmente de temas de trigonometria e foi dedicada ao padre Clavius. É também nessa obra que o autor publicou $\pi$ com 15 casas decimais (VAN ROOMEN, 1593, página não numerada), único fato pelo qual comumente é lembrado na bibliografia referente à história da matemática.

É ainda nessa obra que se iniciam os desafios entre van Roomen e Viète. Nas páginas introdutórias, o matemático belga apresenta o Problema mathematicum omnibus totius orbis Mathematicis ad construendum propositum. Segundo Bien (2007, p. 51), em notação matemática atual, o problema seria encontrar as raízes para a seguinte equação:

$$
\begin{gathered}
x^{45}-45 x^{43}+945 x^{41}-12300 x^{39}+\cdots \\
+95634 x^{5}-3795 x^{3}+45 x=\text { constante }
\end{gathered}
$$

Antes de apresentar o desafio propriamente dito, van Roomen expõe uma lista de estudiosos ilustres de seu tempo, destacando diversos nomes e engrandecendo cada um por seus contributos para a matemática. Sem o intuito de valorizar qualquer um deles em particular, o autor faz propositalmente uma lista alfabética contendo, dentre outros, os seguintes nomes: Clavius, Guidobaldo del Monte (1545-1607), Giovanni Antonio Magini (1555-1617), Ludolph van Ceulen (1540-1610), Simon Stevin (1548-1620), Tycho Brahe (1546-1601), Valentinus Otho (1550-1603), Girolamo Cardano (1501-1576), Luca Pacioli (1447-1517), Nicoló Tartaglia (1499-1557) e Pedro Nunes (1502-1578). A lista de van Roomen contempla ainda o nome de alguns estudiosos de medicina e tipógrafos (VAN ROOMEN, 1593, página não numerada).

Por algum motivo não justificado pelo próprio autor, sua lista não apresenta nenhum grande nome da matemática francesa. Gédéon Tallemant des Réaux (1619-1692), em sua obra Historiettes. Mémoires pour servir à l'histoire du xvii siècle, publicada postumamente em 1834 (tomo segundo, pg. 47-49), conta uma anedota de como o problema pode ter ido parar nas mãos de Viète: teria sido a partir de um convite feito por Henrique IV (1553-1610). O Rei havia recebido a visita de um embaixador em Fontainebleau e, quando saiu para mostrar ao seu anfitrião o que havia de melhor no reino, ele o questiona se havia um grande matemático na França, pois havia visto na obra de van Roomen uma listagem de grandes matemáticos europeus e não havia nenhum nome francês. $\mathrm{O}$ rei chama Viète que rapidamente expõe duas respostas para o problema.

A resposta de Viète foi publicada dois anos depois, em 1595, na obra Ad problema quod omnibus mathematicis totius orbis construendum proposuit Adrianus Romanus 
Francisci Vietae Responsum. Antes de expor sua resposta, Viète (1595, fólio.1 frente) debocha da "nacionalidade" e do sobrenome de van Roomen: "Um belga que se passa por romano; um romano que se passa por um belga; dificilmente um gálico permitiria sua glória ser tomada por um romano ou por um belga". Viète sarcasticamente diz ainda: "Eu, que não me declaro matemático, mas que me deleito com os estudos matemáticos quando estou com tempo livre" e mesmo assim fui capaz de resolver o problema proposto por van Roomen com facilidade (VIÈTE, 1595).

No final da obra, o matemático francês propõe um desafio para van Roomen: a resolução de um dos casos do clássico Problema de Apolônio (VIÈTE, 1595, fólio 14, verso). O referido problema foi proposto e resolvido por Apolônio de Pérgamo (262 a.C190 a.C) ainda na Antiguidade, porém seu trabalho se perdeu e só temos notícia dessa obra devido às menções feitas por Pappus de Alexandria (c. 290 d.C-c. 350 d.C). O problema é o seguinte: dados três objetos do plano - cada um dos quais pode ser um ponto, uma reta ou uma circunferência - construir todas as retas e/ou todas as circunferências tangentes aos três simultaneamente. De todos os casos possíveis, a proposta de Viète para van Roomen se referia ao seguinte caso: "Dados três círculos, descrever um quarto círculo tangente aos três" (VIÈTE, 1595).

A solução parcial para o problema foi publicada por van Roomen em 1596 na obra Problema Apolloniacum. Em seu prefácio, como que para se defender dos sarcasmos de Viète, o autor vangloria os belgas através dos trabalhos do "doutíssimo e dedicadíssimo Ludolph van Ceulen" que, ainda segundo o autor, supera o mérito de Viète. Van Roomen reconhece a distinção de Viète, porém afirma que ele deixou a fama tomar conta de seu ego. Ainda no prefácio, o autor escreve que a matemática não é de opiniões, mas de demonstrações e que a qualidade de seus trabalhos e dos de Viète deve ser julgada por alguém capacitado em matemática e que não seja de origem belga, nem gálica (VAN ROOMEN, 1596, p. 3).

Na carta [18], enviada por van Roomen a Clavius, em 1 de julho de 1597, fica evidente que o tempo não foi suficiente para completar o trabalho e que a publicação foi feita às pressas. Além disso, a solução apresentada não contemplou todos os casos possíveis, mas somente aqueles em que os três círculos dados fossem independentes, ou seja, não tocassem entre si. Ainda nesta carta, fica claro que Clavius auxiliou van Roomen na resolução do problema e que a obra publicada em 1596 agradou ao padre jesuíta (BOCKSTAELE, 1976; GONÇALVES; OLIVEIRA, 2007; GONÇALVES; OLIVEIRA, 2010).

A solução dada por van Roomen não foi considerada válida por Viète, por não poder ser construída com régua e compasso, como tradicionalmente era admitido na geometria clássica. Sendo assim, o matemático francês publicou sua solução na obra Apollonius Gallus em 1600. O próprio título da obra traz novamente uma provocação em relação à "nacionalidade" de ambos os matemáticos: desta vez Viète se vangloria de ter a "solução correta" para o problema e se autointitula "o Apolônio gálico".

No início desta obra, Viète comenta acerca das duas formas de se resolver problemas geométricos: da maneira clássica, ou seja, com régua e compasso e outras formas de se buscar respostas para tais problemas, mas que não são construtíveis com régua 
e compasso (VIÈTE, 1600). Obviamente este segundo modo de se resolver problemas matemáticos é bastante desvalorizado por Viète e por outros matemáticos daquele tempo.

Van Roomen, admirado pelos conhecimentos matemáticos demonstrados por Viète, foi à França para conhecê-lo. Apesar de não ter resquícios desta vista na correspondência existente, ambos teriam se tornado amigos, tanto que Viéte teria pago todas as despesas de viagem de van Roomen (RÉAUX, 1834).

\section{Van Roomen, Scaliger e a quadratura do círculo}

Nas cartas, van Roomen aproveita para comentar com Clavius também acerca do andamento da escrita e da publicação de suas próprias obras. Como podemos ler na carta [19], de 17 de setembro de 1597, nem sempre esta atividade era realizada facilmente. Quando van Roomen estava em vias de publicar sua obra In Archimedis circuli dimensionem, parece ter tido problemas com seu tipógrafo de costume e teve que sair à procura de alguém que imprimisse a obra, entretanto esta empreitada não foi tão fácil.

A ideia de publicar a In Archimedis circuli dimensionem inicia alguns anos antes, por volta de 1594, quando Scaliger publica sua Cyclometrica elementa duo na qual afirma ter encontrado uma solução para o clássico problema da quadratura do círculo. Como van Roomen e outros autores vão argumentar, Scaliger comete diversos erros, de maneira que a solução apresentada na Cyclometrica estava incorreta.

Voltemos ainda mais alguns anos para entender melhor a história. Por volta de 1590, Scaliger já havia distribuido um panfleto escrito em latim e em grego dizendo que tinha encontrado a resposta para os três famosos problemas matemáticos da Antiguidade: a quadratura do círculo, a duplicação do cubo e a trissecção do ângulo. Segundo Bosckstaele (2009), Viète teria refutado Scaliger em $1592 \mathrm{em}$ palestras dadas em Tours e na sua obra Varia responsa, publicada em 1593. Isso não impediu que Scaliger fosse adiante e publicasse sua resposta para a duplicação do cubo na obra Mesolabium e para a quadratura do círculo na Cyclometrica elementa duo, ambas as obras de 1594.

"A solução de Scaliger para o problema da quadratura do círculo pode ser resumida da seguinte maneira. Na primeira parte da Cyclometrica Elementa duo ele foca na circunferência do círculo. De acordo com a proposição VI (p. 31), o quadrado da circunferência de qualquer círculo é dez vezes o quadrado de seu diâmetro. Como consequência, o raio da circunferência de um círculo para seu diâmetro (isto é o que nós chamamos de $\pi$ ) é igual a $\sqrt{10}$. Subsequentemente, Scaliger dá uma construção de uma linha reta igual a circunferência de um círculo (Proposição 7, p. 37). A segunda parte da Cyclometrica Elementa trata da área do círculo. Na visão de Scaliger, a área de qualquer círculo é igual a um retângulo contido pelo lado de um triângulo equilátero inscrito no círculo, e nove décimos do diâmetro (Proposição III, Corolário, p. 80)" (BOCKSTAELE, 2009, p. 436, tradução nossa). 
Scaliger descarta todas as tentativas anteriores de resolver o problema, inclusive critica os trabalhos de Arquimedes (287 a.C-212 a.C). Segundo Bockstaele (2009), van Ceulen foi o primeiro a recomendar que Scaliger não distribuísse a obra, mas ele o teria respondido com "desprezo e escárnio". Segundo Hogendijk (2010), alguns historiadores acreditam que van Ceulen não teria publicado sua refutação ao trabalho de Scaliger, contudo o autor contesta essa vsão e mostra evidências de que isso ocorreu no capítulo 21 da obra Vanden Circkel de 1596.

Van Roomen também tentou advertir Scaliger, pois seria de seu feitio avisar aos autores sobre eventuais erros cometidos. Na carta [1], de 11 de maio de 1592, ao falar da Planisphaeriorum universalium theorica de 1571 de Guidobaldo del Monte, na qual encontrou "um erro na demonstração da construção da elípse", van Roomen afirma que

"Isso [o envio de cartas para avisar aos autores sobre eventuais erros cometidos em suas obras] de fato a mim foi, e ainda agora é habitual, indicar aos próprios autores, se ainda vivem, erros mais leves e que por descuido aconteceu, para que possam ainda publicar seus livros mais corretamente. De fato somos todos humanos, e facilmente todos erramos" (BOCKSTAELE, 1976, p. 93, tradução nossa).

Na carta de outrubro de 1594, a carta [10a], van Roomen comenta para o próprio Scaliger que tem a Cyclometrica em mãos, mas que ainda não teve tempo para realizar a leitura. Na mesma carta, van Roomen menciona que ficou feliz ao receber notícias de Franciscus Raphelengius (1539-1597), impressor da Cyclometrica, que Scaliger admira os trabalhos realizados por ele. Van Roomen agradece e afirma que também tem admiração por Scaliger por ter ouvido a "humanidade [dele] ser proclamada muito frequentemente". Até que ponto estas palavras são sinceras, não temos evidencias (BOCKSTAELE, 1992).

Bocksatele (2009) estima que van Roomen enviou suas considerações sobre a quadratura de Scaliger por volta de novembro de 1594. Nas cartas existentes, podemos menciionar dois trechos em que van Roomen comenta sobre a publicação da Cyclometrica. $\mathrm{Na}$ carta [11], de 20 de novembro de 1594, van Roomen comenta com Clavius que "Joseph Scaliger editou o livro sobre a quadratura do círculo: sobre o qual não esperes alguma opinião minha, do que estou surpreso com este homem ter desejado publicar tais coisas". Na mesma carta, van Roomen se refere ainda à resposta dada rapidamente por van Ceulen (BOCKSTAELE, 1976, p. 113, tradução nossa).

Em março de 1595, van Roomen recebe uma carta de resposta - a carta [14] - na qual o humanista agradece as contribuições feitas por ele. É junto desta carta que Scaliger envia a van Roomen o Appendix ad Cyclometrica sua, publicado no final de 1594, no qual Scaliger corrige alguns de seus erros (BOCKSTAELE, 1992). Porém, o humanista continua a se vangloriar de ter encontrado a solução para a quadratura do círculo e insiste em afirmar que Arquimedes cometeu erros em sua obra. O calvinista pede a van Roomen que divulgue sua nova obra entre aqueles que, "injustamente e desumanamente", o acusam de ter cometido erros.

Sobre isso, na carta [13], de 8 de fevereiro de 1595, enviada para o humanista Justus Lipsius (1547-1606), van Roomen afirma: "Scaliger editou, como entendo, uma 
refutação ao calendário gregoriano, mas julgo essa refutação digna; editou outra obra matemática inscrita Elementa Cyclometrica, nas quais não é encontrado nada além de vãs ostentações e falsos dogmas" (BOCKSTAELE, 1976, p. 116, tradução nossa).

Van Roomen decidiu então escrever uma obra, a In Archimedis circuli dimensionem, na qual mostra detalhadamente os erros da quadratura de Scaliger e de outros estudiosos. A obra fica pronta em 1595, como o autor comenta a Clavius na carta [15] de 3 de outubro de 1595, mas devido à dificuldades para encontrar um tipógrafo, não consegue imprimir a obra naquele momento (BOCKSTAELE, 1976).

Dois anos depois, na carta [19], de 17 de setembro de 1597. Van Roomen detalha alguns aspectos do processo de publicação da referida obra.

"Mas escuta que coisa graciosa. Eu fiz um acordo de impressão com um tipógrafo calvinista genebrino para que produzisse o livro (O fato é que os de Frankfurt descuidaram de minha esperança). Dificilmente os calvinistas suportaram que eu, católico, rejeitasse a doutrina do mais célebre entre os calvinistas, ponto de que muitos me tinham encorajado que desistisse desde o início. E muito mais dificilmente suportaram que aquele livro contra um calvinista fosse impresso na principal cidade dos calvinistas. Assim um tumulto surgiu entre os estudiosos de Genebra, quiseram proibir a impressão do livro e até quiseram que o original fosse suprimido (Eu certamente, de fato descrevera com uma apressada pena, $e$ não tive o tempo necessário para reescrever). Mas o tipógrafo (como foi relatado por mim tanto por ele mesmo como por outros) da obra empreendida pôs-se à disposição do fiel contratador (como eu a ele antes informara). Defendeu que nada estava contido na obra que dissesse respeito à religião ou à saúde da república. O livro foi examinado e, como o tipógrafo defendeu, assim também fora julgado pelos censores. Por isso, tendo todos os estudiosos dedicadíssimos a Scaliger, o tipógrafo recorreu à autoridade de imprimir e produziu mesmo o livro sob o título da cidade de Wurceburgo (como também eu acordara com ele). Mas não pouco errou o tipógrafo no título quando chama a mim professor de matemática aqui em Wurceburgo, porque é nula para mim aqui tal profissão, mas somente de medicina. Chamou-me também "excelentíssimo", o que para minha modéstia costuma ser estranhíssimo. Mas ele dirige a causa do erro para mim, porque eu tinha escrito simplesmente "pelo autor A. Romanus". De fato, ele considerou que esse título é excessivamente de pouco valor" (BOSKSTAELE, 1976, p. 127, tradução nossa).

Neste trecho aparecem evidências que apontam para algunas aspectos de como a religião e a prática científica estava, pelo menos de maneira indireta, entrelaçada. Especificamente no caso da publicação da In Archimedis circuli dimensionem, as questões religiosas poderiam ter impedido, mesmo que demaneira indireta, que esta obra viesse à luz, mas van Roomen conseguiu que os censores liberassem e o impressor também teve 
certa prudência para que não tivessem problemas posteriormente. Toda a polêmica ocorre porque a obra foi publicada em Genebra, uma cidade calvinista. Porém, como é possível ver no frontispício da obra e nos comentários feitos por van Roomen na carta [19], o impressor colocou "Em Wurceburgo", conforme imagem abaixo (BOCKSTAELE, 1976, p. 127).

\section{I $\mathrm{N}$

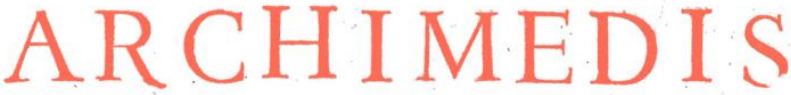 \\ CIR CVLI DIMENSIONEM Expofitio \& Analyfis.}

\section{A P O L O I A P O A R C I ME DE:} ad Clarifiss virum Iofephum Scaligerum.

\section{EXERCITATIONES CY'CLICAE \\ contra Jofephum Scaligerum, Orontium Finzium, \& Raymarum \\ Vrfum, in decem Dialogos diftineta. \\ esters}

$\triangle V T H O R E$ ADRIANO ROMANO EQVITE

Awrato, Matbefean Excellentijsimo Proffjore inu

Academia VV urceburgenfi.

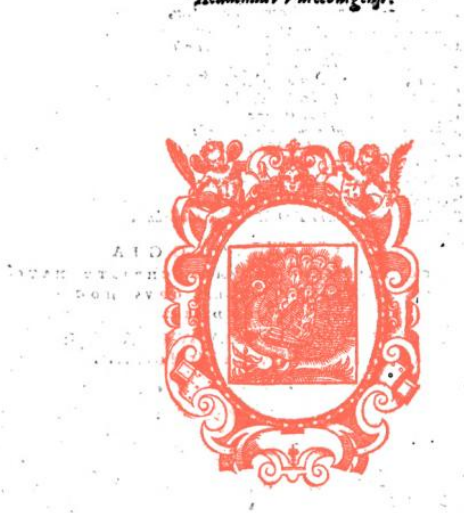

W $V R C E B V R$ l.

ANNOCIDIT XCVII.

Figura 1: Frontisício da obra In Archimedis circuli dimensionem de van Roomen.

Na sua edição crítica da Correspondência de van Roomen, Bockstaele (1976) apresenta uma nota de rodapé à carta [19], contendo um trecho de uma carta de Jacques Esprinchard (1573-1604) enviada para Scaliger enviada em dia 23 de março de 1597, mostrando o outro lado dessa história. 
"Somente vos direi em uma palavra, Senhor, que depois de várias ameaças e perigos iminentes que me coube correr no caminho do Reno, cheguei pela graça de Deus são e salvo a esta cidade de Frankfurt, onde tendo já passado alguns dias e visitado sem compromisso as lojas dos livreiros, eu vi somente um livro contra vós, que é de Adrianus Romanus, o qual ele dedica ao Imperador. Foi impresso em Genebra, ainda que embaixo o impressor tenha colocado: em Wurceburgo. Eu falei com algumas pessoas honestas de Genebra, que me contaram em detalhes como tudo se passou com a impressão do dito livro, e como o senhor de Beze e todos os vossos outros amigos foram à prefeitura para oporem-se e impedirem que o dito livro fosse impresso, a que resistindo o impressor Candolle e apresentando aos senhores aos quais ele lhes mostrava que ele havia já despendido mais de trezentos escudos para fazer as figuras, $e$ que isso seria lhe fazer um grande mal se o livro não se imprimisse, aceitou-se seu pedido, com a condição de que ele não tivesse nenhum ataque contra vós. As mercadorias daqueles de Genebra permaneceram para trás, razão pela qual esse livro não foi visto por ninguém. Vignon, cunhado de Candolle, mostrou-me dois exemplares, dos quais um é para o autor, pelo que ele me disse, e o outro para o bispo de Wurceburgo. Eu tratei por todos os meios de ter um exemplar por qualquer preço que fosse, a fim de vos enviar, mas isso me foi impossível. Disseram-me que o próprio autor o enviará a vós em breve” (BOCKSTAELE, 1976, p. 127, tradução nossa).

Além de comentar sobre a publicação, van Roomen também envia um exemplar para Clavius e comenta sarcasticamente: "Envio minha análise do pequeno tratado de Arquimedes, juntamente com exercícios cíclicos, nos quais verás frivolidades, mas com os frívolos foi conveniente ser frívolo" (BOCKSTAELE, 1976, p. 126, tradução nossa).

A obra é dividia em três partes: a primeira contém o texto grego e uma tradução para o latim da obra Sobre as medidas do círculo de Arquimedes; a segunda é uma Apologia pro Archimedes contra os ataques de Scaliger. É nesta parte também que van Roomen introduz pela primeira vez suas ideias sobre a Mathesis Universalis; por fim, a terceira parte traz análises e refutações das quadraturas propostas por Scaliger, Orontius Finaeus (1494-1555) e Raymarus Ursus (1551-1600) (BOCKSTAELE, 2009; OLIVEIRA, 2015).

Em um trecho da In Archimedis circuli dimensionem, van Roomen também menciona as tentativas de avisar Scaliger para não publicar sua quadratura.

"O obra Cyclometrica de Scaliger mal foi impressa, quando matemático excelentíssimo no mais alto grau de nossos tempos, Ludolph van Ceulen, a tomou em suas mãos, e leu e examinou completamente. Ele encontrou erros importantes, e através de homens doutos, tanto familiares a Scaliger, ele os apresentou. Ao mesmo tempo, o encorajou a suprimi-la, com a obra em mãos antes de ser vendida para alguém, e então com 
razão preservaria sua honra. Riu o homem doutissimo Scaliger, também [disse que] não existiria nehum matemático doutíssimo que despendesse muito tempo, examinar, muito menos, compreender seus escritos. De onde, pouca coisa dese ser feita com o julgamento de algum lutador (pois assim chamava Ludolph, indigno do nome de matemático) que detido com suas ocupações cotidianas, em dez ou doze dias (de fato, Ludolph não superou tanto [tempo]) não poderia examinar essas coisas. Por esta razão, ele queria que Ludolph publicasse suas críticas. Embora Ludoph aceiasse isso como resposta, não parou para encorajar aquele homem duas ou três vezes mais a cuidar melhor de sua honra. Mas em vão" (VAN ROOMEN, 1597, p. 56, tradução nossa).

Uma das controvérsias colocadas em questão é se os números podem ser utilizados ou não nas provas geométricas. Nos Analytica posteriora de Aristóteles (384 a.C-322 a.C), o filósofo afirma que não se deve utilizar números nas demonstrações geométricas e, é seguindo este princípio que Scaliger critica o trabalho de Arquimedes (BOCKSTAELE, 2009). Van Roomen argumenta que ambas as ciências - aritmética e geometria - tem o número como objeto comum, mas que seus usos são distintos. Embora, algumas demonstrações aritméticas possam ter figuras geométricas, elas não necessitam de tal recurso, pois se preocupam em demonstrar as propriedades específicas (como os números primos) ou comuns para todas quantidades (como aquelas referente á soma, diferenças, produtos, razões, proporcionalidades, etc.). Mas, van Roomen sustenta que ainda assim, as demonstrações aritméticas podem fazer uso de fuguras geométricas (VAN ROOMEN, 1597; BOCKSTAELE, 2009).

Em sua Apologia, van Roomen afirma também que os números podem ser tuilizados nas demonstrações geométricas e cita diversos autores contemporâneos que faz este tipo de uso. O matemático belga argumenta que os autores citados usam números para tratar de problemas geométricos que envolvem proporções de linhas, áreas ou corpos. Em trigonometria, o uso dos números para cálculo de tabelas de senos e tangentes é também de grande importância. Van Roomen cita ainda autores que trabalham com estereometria, onde os números também são bastante relevantes (VAN ROOMEN, 1597).

Para convencer Scaliger, van Roomen cita ainda autores que o humanista considera de grande importância, como Euclides e sua célebre obra Elementos. Por fim, van Roomen recorre à própria obra de Scaliger mostrando trechos em que o humanista faz uso de números nas suas demonstrações geométricas (VAN ROOMEN, 1597).

\section{Algumas considerações}

Nos dos debates apresentados - (i) o debate travado por van Roomen e Viète através dos desafios trocados em suas obras matemáticas publicadas no final do século XVI e (ii) a solução dada por Scaliger para a quadratura do círculo assim como sua insistência em rejeitar e batalhar intensamente para provar que as refutações publicadas por diversos autores estavam erradas - aparece claramente a questão do uso da régua e compasso como fundamental para a resolução de um problema geométrico, assim como a validade do uso 
do número nas demonstrações geométricas. Estes fatos mostram como as práticas matemáticas daquele tempo podem se inserir no contexto das instituições mencionadas por Goldstein (2013). São nesses espaços de disputas e controvérsias que se evidenciam que práticas são tidas como válidas dentro da cultura matemática daquela época.

No primeiro caso, percebe-se ainda que, em meio às publicações impressas, há uma prática institucionalizada dominada não somente pelos desafios matemáticos, mas também pelas provocações no que se refere á qualidade e mérito dos trabalhos executados, assim como também os autores incluem em seus escritos comentários irônicos sobre outros assuntos, como suas nacionalidades.

Como dissemos, percebe-se nos trabalhos de van Roomen e de Viéte os modos considerados válidos de se fazer matemática. Sabemos que a geometria grega ainda exercia muita influência sobre as práticas matemáticas do final do século XVI, de modo que, os estudiosos, ao buscarem soluções para problemas geométricos deveriam sempre tomar o cuidado de que suas respostas fossem sempre construtíveis com régua e compasso, o que van Roomen não levou em conta ao apresentar sua solução e a tornou "invalida".

No segundo caso, vemos como van Roomen se insere num debate sobre a validade da resposta de Scaliger sobre a quadratura do círculo. Neste episódio, percebvemos como as soluções dadas também tinham que estar dentro de quesitos matemáticos considerados válidos, como é o caso do uso dos números nas demonstrações geométricas ou do recurso á figuras geométricas em demonstrações aritméticas.

Ambora não detalhamos, é possível encontrar ainda menções aos debates sobre a construção de tabelas trigonométricas cada vez mais apuradas. Sendo um assunto de grande interesse de van Roomen, ele teve o cuidado de acompanhar de perto os estudos de diversos autores. Na carta [24], por exemplo, aparece uma crítica detalhada das tabelas desenvolvidas pelo matemático jesuíta Christoph Grienberger (1561-1636).

Nas cartas há também menções aos intensos debates em que estiveram envolvidos Clavius, de um lado, e Scaliger e Viète, de outro, discutindo acerca da reforma do calendário, promulgada em 1582 pelo Papa Gregório XIII (1502-1585). As mudanças não foram aceitas facilmente e nem foram incorporadas em toda a Europa de uma só vez. O debate continuou a ocorrer por muitos anos, sendo mencionado várias vezes na Correspondência de van Roomen. Em 1600, Viète publicou uma obra chamada Relatio Kalendarii vere Gregoriani, na qual condena o método "claviano" da reforma do calendário e propõe o "verdadeiro Calendário Gregoriano" feito por ele mesmo. (BOCKSTAELE, 1976).

Percebemos então, que muitos matemáticos, ao questionarem a validade e mérito dos trabalhos e das soluções apresentadas por outros, dispõem se a travar disputas para mostrar as suas opiniões. Isso gera uma corrente de atraques, contra-ataques, contradesafios, réplicas e tréplicas.

Nestas disputas, os ataques podem ir além do campo específico do conteúdo e das práticas matemáticas, os insultos podem tornar-se abertos e as discórdias entre os personagens avançam em outros assuntos, como nacionalidades, religiões etc.

Pensamos então que a prática matemática dos europeus dos séculos XVI pode ser pensada como uma instituição que merece ser investigada em diversos aspectos, sendo um 
desses as disputas, desafios e controvérsias estabelecidas entre eles, seja através das correspondências, seja nas obras impressas.

\section{Bibliografia}

BIEN, Reinhold. 2007. Viète's Controversy with Clavius over the Truly Gregorian Calendar. In: Archive for History of Exact Sciences. vol. 61, 39-66.

BOCKSTAELE, Paul. 1976. The Correspndence of Adriaan van Roomen. In: LIAS Sources and Documents Relating to the Early Modern History of the Ideas. vol. 3, 85-129 e 249-299.

BOCKSTAELE, Paul. 1992. The Correspndence of Adriaan van Roomen - Corrections and Additions. In: LIAS - Sources and Documents Relating to the Early Modern History of the Ideas. vol. 19, 3-20.

BOCKSTAELE, Paul. 2009. Between Viète and Descartes: Adriaan van Roomen and the Mathesis Universalis. In: Archive for History of Exact Sciences. vol. 63, n. 4, 433-470.

GIL, Paulo Duarte Bastos. 2001. François Viète: o despontar da álgebra simbólica. Mestrado em Matemática. Universidade do Porto.

GOLDSTEIN, Catherine. 2013. Routine Controversies: Mathematical Challenges in Mersenne's Correspondence. In: Revue d'Histoire des Sciences. vol. 66, n. 2, 249-273.

GONÇALVES, Carlos Henrique Barbosa; OLIVEIRA, Zaqueu Vieira. 2007. Geometria, Reforma e Contra-Reforma na Carta de Adriaan van Roomen para Clavius, de 1 de julho de 1597. In: Circumscribere: International Journal for the History of Science. vol. 3, 13-19.

GONÇALVES, Carlos Henrique Barbosa; OLIVEIRA, Zaqueu Vieira. 2007. A Atividade Matemática de Adriaan van Roomen. In: Revista Brasileira de História da Matemática. vol. 10, n. 20, 147-164.

HOGENDIJK, Jan P. 2010. The Scholar and the Fencing Master: the exchanges between Joseph Justus Scaliger and Ludolph van Ceulen on the circle quadrature (1594-1596). In: Historia Mathematica, vol. 37, 345-375.

LATOUR, Bruno; WOOLGAR, Steve. 1997. A Vida de Laboratório: a produção dos fatos científicos. Tradução de Angela Ramalho Viana. Rio de Janeiro: Relume Dumará.

MERTON, Robert King. 1973. The Normative Structure of Science. The Sociology of Science: theoretical and empirical investigations. Chicago and London: The University of Chicago Press, pp. 267-278.

OLIVEIRA, Zaqueu Vieira. 2015. A classificação das disciplinas matemáticas e a Mathesis Universalis nos séculos XVI e XVII: um estudo do pensamento de Adriaan van Roomen. Tese (Doutorado em Educação Matemática) - Universidade Estadual Paulista.

RÉAUX, Tallemant des. 1834. Historiettes de Tallemant Des Réaux. Mémoires pour servir à l'histoire du xviie siècle. 6 tomos. Paris: Alphonse Levavasseur.

RULAND, Anton. 1867. Adrien Romanus Premier Professor à la Faculté de Médicine de Würzbourg. In: Le Bibliophile Belge, vol. 2, 56-100, 161-187 e 256-269.

VAN ROOMEN, Adriaan. 1593. Ideae Mathematicae Pars Prima. Antuérpia: Johannes van Keerbergen, 1593.

VAN ROOMEN, Adriaan. 1596. Problema Apolloniacum. Wurceburgo: Georgius Fleschmann. 
VIÈTE, François. 1595. Ad problema quod omnibus mathematicis totius orbis construendum proposuit Adrianus Romanus Fracisci Vietae Responsum. Paris: Jametium Mettayer.

VIÈTE, François. 1600. Apollonius Gallus. Paris: David le Clerc.

\section{Zaqueu Vieira Oliveira}

Universidade de São Paulo - USP

E-mail: z.zaqueu@usp.br
Thomás A. S. Haddad

Universidade de São Paulo - USP

Email: thaddad@usp.br 


\section{As Cartas}

A seguir apresentamos, lado a lado, texto original em latim e a tradução para o português das cartas que estudamos para a elaboração deste artigo. A trascrição foi feita a partir da edição crítica de Paul Bockstaele $(1976 ; 1992)$ e a tradução está acompanhada de notas de rodapé explicativas para auxiliar o leitor na compreensão do contexto das cartas, especialmente no que diz respeito aos titulos de obras citadas e seus autores.

Uma das cartas, a de 1 de julho de 1597, já foi apresentada em um artigo anterior (GONÇALVES; OLIVEIRA, 2007), mas as demais são inéditas.

Também é importante mencionar que quando necessário, incluímos palavras na tradução as quais não aparecem no texto original. As mesmas estão indicadas entre colchetes. 


\section{Carta 10a}

Clarissime vir, finitis jam Francofurtanis nundinis, Francofurtum veni, ubi inter nundinarum reliquias inveni librum ab Ecc. vestra conscriptum de quadratura circuli, quem sanè longo jam tempore desideravimus. Nihil autem de eo hoc tempore scribo; ubi ocium ${ }^{1}$ nactus fuero totum perlegam, atque quid de quadratura inventa sentiam breviter perscribam. Quod D. Raphalengius mihi scribat, me ab Ecc. vestra diligi, est quod mihi gratuler, non quod in me tale quid esse sentiam, ob quod me amore dignum judicem, sed quod humanitatem vestram quam sepissime praedicari intellexi, jam ipse sentiam. Unum porro super est quod ab Ecc. vestram petam. Retulit mihi hodie D. Nicolaus Bassaeus meditari Ecc. vestram novam librorum de temporum emendatione editionem: qua in re non dubium quin Bassaeo (qui omne adhibita diligentia, magnisque impensis libros eos ante annum edidit) insigne inferretur damnum: praecipuè cum eorundem librorum non exiguam habeat quantitatem. Rogat ergo Ecc. vestram, ut Christianae pietatis intuitu, novam eam editionem ad tempus aliquod differre dignetur. Quod speramus Ecc. vestram ideò facturam libentius, quòd eam variorum aliorum librorum (quos jam conscripsit, quotidiéque scribit) editione occupatam intelligamus. Si qua autem in re tum ego tum Bassaeus servire Ecc. vestrae poterimus, semper praesto erimus. Si quos libros habeat in sua officina Bassaeus, eos muneris loco Ecc. vestrae mittere cupit, mode eorum ad eum mittatur catalogus. Quod operis de temporum emendatione praefixa sit praefatio, id non ipsi sed Typographo imputandum est, uti mihi retulit ipse.

Vale Vir Clarissime. Raptim IIII Nonas Octobris. $\infty$ DXCIIII. Francofurti in aedis Bassaeo.

Ecc. Vestrae addictissimus

Adrianus Romanus

\footnotetext{
${ }^{1} \mathrm{O}$ correto parece ser otium.
} 


\section{Carta 10a}

De van Roomen em Frankfurt para Scaliger em Leiden.

4 de outubro de 1594

Homem ilustríssimo, já terminada a feira [de livros] de Frankfurt ${ }^{2}$, vim a Frankfurt, onde entre o que sobrou da feira encontrei o livro escrito por vossa Ex[celência] sobre a quadratura do círculo $^{3}$ que, na verdade, desejamos já há muito tempo. Por outro lado, nada escrevo sobre isso neste momento; quando tiver encontrado tempo eu o lerei todo e transcreverei brevemente o que pensar sobre a quadratura encontrada. Que o Sr. Raphelengius ${ }^{4}$ escreva a mim que eu seja admirado por vossa Ex[celência], é o que me alegra, não porque em mim eu pense ser algo assim, porque me julgue digno de amor, mas porque eu percebi vossa humanidade ser proclamada muito frequentemente, agora eu mesmo pense. Continuando, resta uma coisa que pedirei a vossa Ex[celência]. O Sr. Nicolas Basseus ${ }^{5}$ entregou a mim hoje para vossa Ex[celência] examinar a nova edição dos livros sobre a correção dos tempos ${ }^{6}$, em qual coisa não é dúbio que ao insigne Basseus (que com toda diligência empregada e com grandes despesas editou esses livros antes de um ano) recaia uma perda, sobretudo porque não tenha uma pequena quantidade dos mesmos livros. Portanto, [ele] roga a vossa Ex[celência], que seja digno de ser considerado da piedade Cristã, difundir essa nova edição em algum momento. Por causa disto esperamos que vossa Ex[celência] há mesmo de fazer isso de boa vontade, porque o percebemos ocupado com a edição de outros vários livros (os quais já escreveu e escreve todos os dias). Se por outro lado nessas coisas tanto eu quanto Basseus pudermos servir a vossa Ex[celência], sempre estaremos à disposição. Caso Bassaeus tenha em sua oficina alguns livros, deseja-os enviar a vossa Ex[celência] no lugar de um presente: basta que o catálogo deles seja enviado a ele. Que o prefácio da obra sobre a correção dos tempos seja no princípio, isso não ao mesmo, mas ao tipógrafo deve-se imputar, como o mesmo respondeu a mim.

Passe bem ilustríssimo homem. Rapidamente no dia 4 de outubro de 1594. Na habitação de Basseus em Frankfurt.

Dedicadíssimo à Vossa Ex[celência] Adriaan van Roomen

\footnotetext{
${ }^{2}$ A feira de livros de Frankfurt tem uma tradição de mais de 500 anos. Antes da ser um local para a venda e difusão de textos escritos, a cidade já era palco de uma importante feira de manuscritos. A primeira feira de livros ocorreu em 1454, organizada por livreiros locais logo após Johannes Gutenberg (1400-1468) ter desenvolvido os tipos móveis. Se tornou importante local de divulgação de livros, ocupando local de destaque neste ramo até o final do século XVII, quando a feira de Leipzig ganha força.

${ }^{3}$ Van Roomen se refere a Cyclometrica elementa duo de Scaliger.

${ }^{4}$ Franciscus Raphelengiu, também conhecido por Frans van Ravelingen, foi humanista e orientalista. Foi o impressor da obra Cyclometrica Elementa duo de Scaliger (BOCKSTAELE, 1992).

${ }^{5} \mathrm{Na}$ segunda metade do século XVI, houve vários impressores e livreiros de sobrenome Basseus. Um dos mais importantes foi Nicolas Basseus (15??-1599) que se instalou em Frankfurt por volta de 1560, onde foi tipógrafo, editor e livreiro. Basseus foi amigo de van Roomen e foi impressor de algumas de suas obras, entre elas o Parvum Theatrum Urbium de 1595 (BOCKSTAELE, 1976).

${ }^{6}$ Van Roomen se refere ao De emendatione temporum de Scaliger impresso primeiramente em 1583 e, depois, uma segunda edição em 1593. Uma terceira edição mais aprimorada foi impressa posteriormente em 1598 (BOCKSTAELE, 1992).
}

RBHM, Vol. 18, n 36 , p. 77-115, 2018 


\section{Carta 14}

Iosephus Scaliger Julii Caesaris Filius Adriano Romano suo Salutem. Puto meas literas tibi redditas esse una cum appendicibus ad Cyclometrica mea: Ex quibus potuisti animadvertere quam iniquus sim meis erroribus neque opus esse alio castigatore, quam me ipso. Sed sane opus mihi erat aliis lectoribus, quam quos hactenus nactus sum ubique; sed praesertim apud vos, ubi passim Cyclometrica nostra ita accipiuntur, ut non humanitus errasse, sed lege Majestatis commisisse videar, \& nihil mitius mihi expectandum sit, quam ut sine provocatione poenas dem, ut homini libero ne ad respondendum quidem sit receptus. Tu scis de quibus loquor, \& qui sunt ii, qui literis suis vulgo quotidie de nobis ea disserunt, quibus ipsi potius digni sunt. Non agam cum ipsis praecise, ut ipsi faciunt. nondum enim dies cessit. Accipe interea hanc diatribam, quam tibi mitto, in qua non solum videbis, quam falsi sint, qui Archimede magistro, circulum aequalem faciunt rectangulo sub semidiametro $\&$ semiperipheria contento, sed etiam quam male existimationi suae consuluisse videntur, qui non capere potuerint quod \& puero planum fecimus. Rem utilissimam proposuimus. ipsi eam obtrectationibus suis eludere conantur. Volsellis pugnant, non gladiis. Lecta mea diatriba, teipsum judicem fero, ne inhumane mecum experiuntur, qui ea vellicant, quae aut non intelligunt, aut si intelligunt, nolunt probare, ne cogantur quae pueri didicere, senes

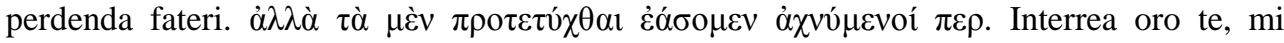
Romane, si quis locus est humanitati, literarum vinculo, sacris Matheseos, ut diligenter perpendas ea quae in diatribam hanc conjecimus, \& ut non solum tibi, sed \& aliis scriptam esse scias. Propterea eam illis communica, quos quamvis nobis iniquiores esse sciveris (ut sane inhumani sunt, qui de homine non ita merito prave $\&$ sentiunt, $\&$ argutantur,) tamen ab his studiis alienos non esse scietis, imo potius quos tibi constabit solide de his rebus judicare posse. De paralogismo Archimedis dubitare non potes, \& hoc \& alia quae ad

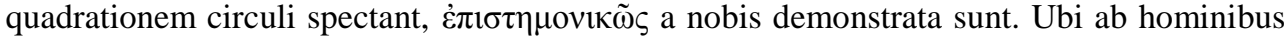
prave tenacibus expressero non circulum quadrasse (velint nolint, hoc fateantur necesse tandem est.) postea ad reliqua pergemus. Errores nostros tollemus; eos qui videntur, \& non sunt, expoliemus. Tu interea mi Romane, clementius de nobis judica, quam hactenus fecisti. Ego libertatem amo, sed intra modum, \& eam quidem quae homine ingenuo digna est. 


\section{Carta 14}

De Scaliger em Leiden para van Roomen em Wurceburgo.

31 de março de $1595^{7}$.

Joseph Scaliger, filho de Júlio César ${ }^{8}$, saúda seu Adriaan van Roomen. Julgo que minhas cartas foram entregues a ti juntamente com os apêndices da minha Cyclometrica ${ }^{9}$, a partir dos quais pudeste observar quão hostil eu sou com meus erros e não pudeste ser útil a outro censor senão a mim mesmo. Mas, certamente meu trabalho era para outros leitores que até o momento os alcancei em todo lugar. Mas, especialmente junto de vós, onde em qualquer lugar, nossa Cyclometrica é assim aceita, como se eu não [fosse] humano por ter errado e tivesse infringido uma lei da Majestade. E nada se deva esperar a mim mais suave do que as penas que eu cumpra, como que sem provocação, como se fosse um recurso para não responder em absoluto a um homem livre. Tu sabes de que coisas falo e quem são que, em suas cartas abertamente, dia a dia, disseram essas coisas de nós, das quais eles mesmos são mais dignos. Não agirei em relação a eles em poucas palavras, como eles mesmos fazem. Na verdade o dia ainda não cessa. Recebe durante este tempo esta discussão, que envio a ti, na qual não somente verás que sejam falsas as coisas, que pelo mestre Arquimedes fazem o círculo igual ao retângulo contido pelo semidiâmetro e pela semiperiferia, mas também que parecem ter examinado sua má estimativa, que [muitos] não puderam compreender o que fizemos claro também para uma criança. Coisa utilissima propomos. Eles mesmos esforçam-se por eludí-las com suas calúnias. Combatem com pinças, não com espadas. Lida minha discussão, levo o julgamento a ti mesmo, nem duramente comigo experimentam, quem combate essas coisas, que ou não compreendem, ou se compreendem, não querem achar bom, nem seja concluído que as coisas que as crianças disseram os velhos confessam ter perdido. "No entanto, essas coisas deixaremos ser como passado e feito"10. Enquanto isso, peço-te, meu van Roomen, se alguém é lugar para a humanidade, para o vínculo das letras, para as sagradas matemáticas, que examines as coisas que diligentemente reunimos nessa resposta e que saibas que foi escrita não somente para ti mas também para outros. Por causa disso, comunica àqueles que souberes que de alguma forma são injustos conosco (de forma que são muito desumanos aqueles que pensam e tagarelam assim sem mérito sobre um homem), ainda que não sejam alheios a esses estudos, ao contrário, mais àqueles que a ti constar que podem julgar solidamente estas coisas. Sobre o paralogismo de Arquimedes não podes duvidar, e isto e as outras coisas que olham para a quadratura do círculo, para nós são demonstradas cientificamente. Quando eu tiver expressado que o círculo não foi quadrado por homens erradamente tenazes (queiram [ou] não queiram, ainda que admitam que isso é necessário), procederemos depois para as coisas restantes. Retiramos os nossos erros; melhoraremos aqueles que parecem e não são. Tu, entretanto, meu van Roomen, julga sobre nós mais clementemente do que até agora fizeste. Eu amo a liberdade, mas dentro de um limite, e ela mesma que é digna de um homem generoso.

\footnotetext{
${ }^{7}$ Esse ano não é mencionado na data da carta, mas é atribuído devido a evidências internas (BOCKSTAELE, 1976).

${ }^{8}$ Julio Cesar Scaliger (1484-1558) foi um escritor e médico italiano.

${ }^{9}$ Aqui Scaliger se refere ao Appendix ad cyclometrica sua.

${ }^{10}$ Trecho da Ilíada de Homero, livro 19, linha 65.
}

RBHM, Vol. 18, n 36 , p. 77-115, 2018 
Si me amas, rescribes ad ea quae tibi mitto. Non enim tanti sunt, neque tot errores nostri, quanti \& quot vobis summis Criticis videntur. Vale. Lugduni Batavorum. pridie calendas Aprilis stylo novo. Misi tibi Hyppolyti Episcopi Canonem cum appendicibus. Meliorem in partem illud opusculum accipe, quam Cyclometrica nostra: si bene assecutus fueris diatribam, quam tibi mitto, habes quod poenitentiam ex te exprimat judicii, quod de me fecisti. Sane omnes boni $\&$ docti sciunt me humanius accipiendum fuisse. Iterum vale. 
Se gostas de mim, reescreve para essas coisas que a ti envio. De fato, não são tantas, nem tantos os erros nossos quão grandes e quantos parecem por suas altas críticas. Passa bem. Leiden. Primeiro dia das calendas de abril no estilo novo. Enviei para ti o Cânon do Bispo Hipólito com apêndices ${ }^{11}$. Toma aquele opúsculo em uma parte melhor do que a nossa Cyclométrica. Se tu tiveres entendido bem tens a disputa, que a ti envio, que expressa arrependimento a partir de ti do juízo que sobre mim fizeste. Todos os bons e doutos sabem que eu fui gentil para ouvir. Mais uma vez, passa bem.

${ }^{11}$ Aqui van Roomen se remete a obra Hippolyti episcopi Canon paschalis cum Iosephi Scaligeri comentario de 1595

RBHM, Vol. 18, n 36, p. 77-115, 2018 


\section{Carta 18}

Reverende admodum in Christo Pater. Accepi literas Reverendae Paternitatis vestrae datas $4 \mathrm{Kal}$. Maij, sesquimense post datum. Ex quibus intelligo nullas accepisse Reverentiam vestram a me literas. Doleo. Scio, me nundinis ultimis autumnalibus per Bibliopolam Belgam cognomine Brechtanum qui negocia Basae agit Francofurti, misisse literas, una cum libellis exiguis, nempe Jacobi Christmanni librum de circuli quadratura, et Petisci cujusdam Trigonometriam, nescio an aliqua alia.

Hisce ultimis nondinis etiam literas dedi eidem et adjunxi librum Belgico sermone editum Ludolfi van Collen, de circulo et usura, in quo polygonorum omnium a triangulo usque ad 80 laterum figuram calculatus est latera, et rationem perimetri circuli ad diametrum exhibuit accuratiorem quam ea sit quam ego, in libris Methodi proposui. Capita praecipua Scaligeri confutat. Hunc librum Ludolfus ipse voluit per me mitti Reverendae Paternitatis vestrae.

Antea longo tempore non scripsi, quia intellexeram Reverendam Paternitatem vestram concessisse Neapolin valetudinis recuperandae ergo.

Ad Staticem Stevinij quod attinet, non facile in latinam linguam vertetur propter terminos quibus utitur, qui cum vario modo sint compositi, non facile Latine redderentur v. g. Rechthefwicht, Scheefhefwicht etc. ubi quod syllabae tot dictiones, priorem ad verbum ita redderem recte-elevandum-pondus, alterum oblique-(sive ad obliquos angulos) elevandumpondus. item recht-dael-wicht hoc est recte-dimittendum-pondus. Verum eorum loco oporteret interpretem assumere alios terminos, aut uti circumscriptione.

Quod placeat Reverendae Paternitati solutio problematis Vietae est quod mihi congratulor. Ad casum quod attinet is a Reverenda Paternitate vestra proponitur talis Tangant sese interius duo circuli etc. et vult ostendere Reverenda [Paternitas] vestra circulum tertium cum quarto consistere in eadem ellipsi, id sane verissimum est. Neque dumtaxat si circuli ij sese tangant, verum etiam si non tangant. Similiter id ipsum verum est in meniscis sive lunulis quibus si inscribantur quotcunque circuli ita ut duos circulos lunulum terminantes tangant omnes ij necessario erunt in eadem ellipsi. 


\section{Carta $18^{12}$}

De van Roomen em Wurceburgo para Clavius em Roma.

1 de julho de 1597.

Padre muito reverendo em Cristo Pai, recebi as cartas de vossa Reverenda Paternidade de 28 de abril, um mês e meio depois de enviadas, a partir das quais deduzo que vossa Reverência não recebeu nenhuma carta de mim. Lamento. Sei que enviei, pelo livreiro belga de sobrenome Brechtanum - que mantém negócios com o Basseus em Frankfurt -, na última feira do outono, cartas, juntamente com uns poucos livros, a saber, o livro de Jacob Christmann sobre a quadratura do círculo e a Trigonometria de um certo Pitiscus, mas não sei de nenhuma outra coisa.

Nesta última feira, também dei cartas para ele e juntei o livro escrito em belga por Ludolph van Ceulen, sobre o círculo e os juros ${ }^{13}$, em que calculou os lados de todos os polígonos desde o triângulo até a figura de 80 lados - e exibiu a razão entre o perímetro do círculo e o diâmetro mais precisamente do que aquela que eu propus no livro do Método ${ }^{14}$. Ele refuta os principais capítulos de Scaliger. O próprio Ludolph quis que esse livro fosse enviado por mim a vossa Reverenda Paternidade.

Antes disso, por muito tempo não escrevi, porque imaginava que vossa Reverenda Paternidade estava no caminho de Nápoles, em razão da saúde que devia ser recuperada.

No que diz respeito à Estática de Stevin ${ }^{15}$, não será facilmente traduzida para a língua latina, por causa dos termos de que se serve, que sendo compostos de vários modos, não serão facilmente traduzidos para o latim: por exemplo, Rechthefwicht, Scheefhefwicht etc., em que há tantas palavras quanto sílabas. Assim, o primeiro termo ficaria traduzido literalmente por recte-elevandum-pondus e o outro oblique-(ou seja, de ângulos oblíquos) elevandum-pondus. Do mesmo modo recht-dael-wicht, isto é, recte-dimittendum-pondus. Mas, em vez disso, convém que o tradutor empregue outros termos, ou como que uma paráfrase.

Fico contente que a solução do problema de Viète agrade à Reverenda Paternidade. A esse respeito, é proposto por vossa Reverenda Paternidade que tangenciem-se interiormente dois círculos etc. e vossa Reverenda [Paternidade] quer mostrar que o terceiro círculo está com o quarto na mesma elipse [figura 2]. Isso é muitíssimo verdadeiro. E não somente se esses círculos forem tangentes, mas também se não forem [figuras 3 e 4]. De modo semelhante, isso mesmo é verdadeiro nos meniscos ou lúnulas nos quais - se são inscritos quantos quer que sejam os círculos, de forma que assim tangenciem dois círculos que limitam a lúnula eles necessariamente estarão na mesma elipse.

\footnotetext{
${ }^{12}$ Sobre esta carta, ver também Gonçalves e Oliveira $(2007 ; 2010)$.

${ }^{13}$ Aqui van Roomen se refere a obra Vanden Circkel de van Ceulen.

${ }_{15}^{14}$ Segundo Bockstaele (1976), aqui van Roomen se refere a sua obra Ideae mathematicae pars prima.

${ }^{15}$ Aqui van Roomen se refere a obra De Beghinselen Der Weeghconst de 1586 de Simon Stevin (BOCKSTAELE, 1976).
}

RBHM, Vol. 18, no 36, p. 77-115, 2018 
Verum idipsum licet mihi notissimum sit ut patet ex exemplari meo quod Typographo exhibuerim, non tamen potuit imprimi ob tempore angustiam, volebam namque ipsi Vietae respondere iisdem nondinis, quare quod potui edere edidi. Nempe Datis tribus circulis a seinvicem liberis hoc est seinvicem non continentibus secundum totum aut secundum partem invenire quartum, reliquam vero partem servare volui in aliud tempus.
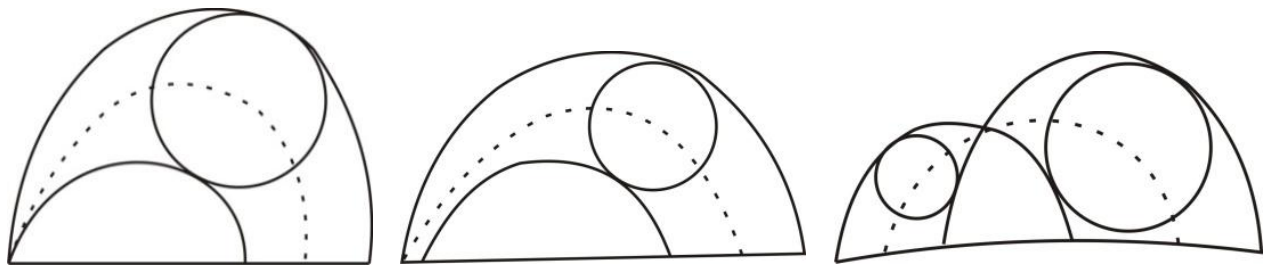

Notandum tamen quod si circuli duo eodem centro descripti sint ut in quarta figura tunc lineam centra continentem esse circulum.

Si itaque mentem meam inspiciat, nempe quos circulos tres assumpserim in lemmatibus meis, videbit casus hosce quatuor esse extra eadem; ideo alio pertinere.

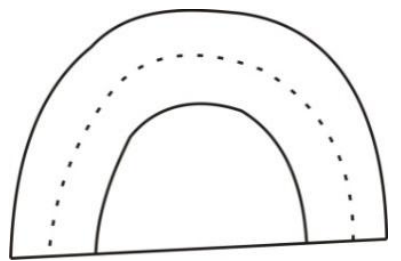

Interim gratiam ago Reverentiae vestrae quod me admonuerit; inde enim colligo studium Reverentiae suae erga me.

Unum tamen celare non possum, mirari me in schemate ductum hyperbolae FM. Nam cum tertium circulum antea assumpsisses COF qui contingeret circulum AEFG in puncto F, assumis deinde hyperbolam FM tanquam si ea hyperbole deberet transire per contactum circulorum AEF et FOC. quod non facile admiserim. Sed existimo factum esse per festinationem.

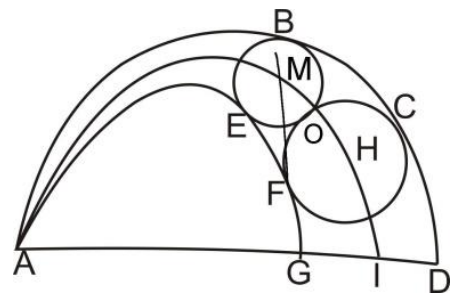


Mas ainda que isso mesmo seja muitíssimo conhecido por mim, como está claro em meu exemplar exibido ao tipógrafo, ainda assim não pôde ser impresso, por causa da estreiteza com relação ao tempo, pois queria responder ao próprio Viète na própria feira, razão pela qual publiquei o que pude publicar - a saber "dados três círculos reciprocamente livres, ou seja, não contendo um ao outro segundo o todo ou segundo a parte", encontrar um quarto mas quis reservar a parte restante para outro momento.
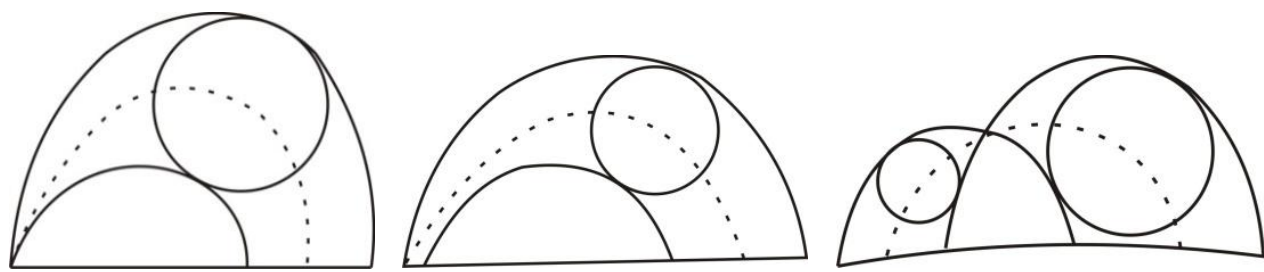

Deve-se notar, ainda, que se dois círculos são descritos com o mesmo centro, como na quarta figura, então a linha que contém os centros é um círculo [figura 5].

E se, dessa forma, observa minha intenção, a saber, quais três círculos assumi em meus lemas, verá que esses quatro casos estão fora dela; por isso mesmo pertencem a outro lugar.

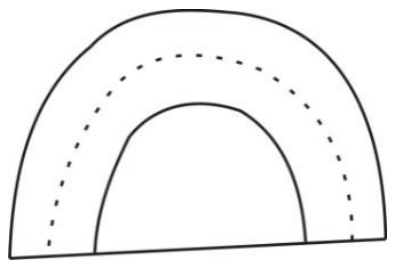

Por enquanto, agradeço a vossa Reverência porque me aconselhou; razão por que, de fato, abraço o estudo de sua Reverência para mim.

Somente não posso deixar de me admirar da hipérbole FM que conduzi no esquema [figura 6]. Pois, porque tomastes antes disso o terceiro círculo COF, que encontra o círculo AEFG no ponto $\mathrm{F}$, tomas em seguida a hipérbole FM como se essa hipérbole devesse ir através do contato dos círculos AEF e FOC. O que eu não faria facilmente. Mas imagino que por causa da pressa.

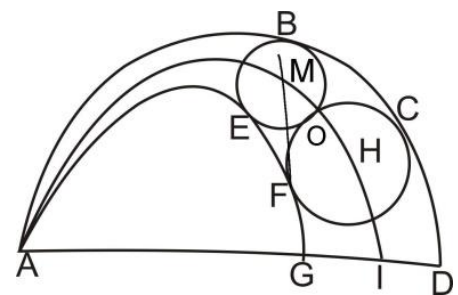

RBHM, Vol. 18, nº 36, p. 77-115, 2018 
Quaeris quid faciat Scaliger. Inquisivi. Intelligo eum occupari in editione librorum de emendatione temporum quos omnino de novo cudit. Vultque satisfacere omnibus qui eum nixi sunt oppugnare. Dicitur etiam cum Raphelengio occupari in Grammatica Arabica concinnanda quam edere velint. De Geometricis nihil intelligo nisi quod maneat in sua opinione pertinax et quotidie adhuc se inventorem quadraturae glorietur.

Opusculum meum quo appendicem ejus examinavi, prodiit. Mittam sequentibus nondinis. Puto me appendici ita me satisfecisse, ut vix quippiam de ea dicendi supersit.

Ludolfus van Collen occupatur in Algebra sua concinnanda, et in ordinem redigenda. Opus erit magnum, doctrina vera, stÿlus, ut scribit, non doctus, sed tamen facilis.

Vieta et ipse Algebram promittit.

Postquam ediderit uterque sua, facile erit Methodo Vietanae (Nam ego vix plura quam Methodum ab eo expecto) doctrinam accomodare Ludolfianam, quam solidam et exactam (licet barbaro more uti hactenus conscripta sunt) fore non dubito.

Nunc ad opus Palatinum venio. Scribit Reverentia vestra, sinus, tangentes, et secantes, in postremis notis deficere a vero respectu sinus totius 10000.0000 .00 partium. Ego sane facto diligenti examine errorem eum in sinibus iis non inveni, praeter errores typographicos quorum aliquot in meo exemplari correxi. At in tangentibus et secantibus aliter sese res habet. Nam tangentes non in postremis tantum notis deficiunt, sed aliquando in tribus, quatuor, quinque et sex notis. Atque ex hisce tangentes per prosthaphaeresin compositi sunt secantes.

Ego id ipsum scripto ad eum misso duorum foliorum chartae ostendi. Verum responsum non accipio.

Ad meas chordas quod attinet, in iis a bienio non progressus sum quia speraveram operis Palatini majorem perfectionem in tangentibus et secantibus. Tandem cum semel e manibus abjecissem nondum resumpsi; imo labores taedet potissimum cum nullum mihi sit calculatorum subsidium. Ideo gratulor mihi de opere a vobis eo dedicto. Sane id erit heroicum neque cum ullo opere hactenus edito comparandum. 
Indagas o que faz Scaliger. Interroguei. Sei que ele está ocupado com a edição de livros sobre a correção dos tempos ${ }^{16}$ que novamente compõe. E deseja satisfazer todos que a ele tentam perseguir. É dito também que um Raphelengius está ocupado na Gramática Arábica que querem publicar ${ }^{17}$. Sobre a geometria nada sei, a não ser que permaneça firme na sua opinião e que até agora se vanglorie cotidianamente de ser o inventor da quadratura.

Segue um opúsculo meu no qual examinei o apêndice dele. Enviarei na próxima feira. Penso assim ter ficado satisfeito com o apêndice, de forma que quase não sobra o que falar dessas coisas.

Ludolph van Ceulen está ocupado na produção de sua Álgebra e na disposição em que deve ser escrita. A obra será grande, o método verdadeiro, o modo como escreve não douto, mas fácil.

Também o próprio Viète promete uma Álgebra ${ }^{18}$.

Depois que cada um publicar suas coisas, o Método (Pois eu dificilmente espero dele mais do que um Método) de Viète deverá facilmente acomodar a doutrina ludolfiana, que não duvido que seja sólida e exata (ainda que somente sejam escritas em uma língua bárbara).

Agora chego ao Opus Palatinum ${ }^{19}$. Vossa Reverência escreveu que senos, tangentes e secantes são deficientes nas casas finais em relação ao seno total verdadeiro de 10 bilhões de partes. Eu, por um examine muito cuidadoso, não descobri erros nesses senos, exceto erros tipográficos, dos quais corrigi um certo número em meu exemplar. Mas, por outro lado, nas suas tangentes e secantes, a coisa se dá diferentemente. Pois não só as tangentes são deficientes nas casas finais, mas também algumas vezes em três, quatro, cinco e seis casas. E a partir destas tangentes são compostas as secantes por prostaférese.

Eu mostrei isso mesmo por um escrito de duas folhas de papel enviado a ele . Mas não recebo resposta.

No que diz respeito às minhas cordas, não progredi nelas durante o biênio, porque esperara maior perfeição do Opus Palatinum nas tangentes e secantes. Enfim, porque as afastei simultaneamente das mãos, ainda não retomei; muitíssimo me enfadam os trabalhos, principalmente porque não tenho nenhuma ajuda de calculadores. Por isso, fico feliz com a obra por ele dedicada a vós. Verdadeiramente será algo heróico, e não deve ser comparada a nenhuma obra editada até o momento.

\footnotetext{
${ }^{16}$ Aqui van Roomen se refere à terceira edição da obra De emendatione temporum de Scaliger que estava sendo preparada e foi impressa em 1598 (BOCKSTAELE, 1976).

${ }^{17}$ Sabe-se que Scaliger estudou diversas línguas, como hebreu e árabe, mas não há informações acerca desta obra.

${ }^{18}$ Segundo Bockstaele (1976), aqui talvez van Roomen esteja se referindo a obra De aequationum recognitione et emendatione tractatus duo de Viète, impressa postumamente em 1615.

${ }^{19}$ A obra mencionada é Opus palatinum de triangulis George Joachim Rheticus terminada por Valentinus Otho, seu aluno, e publicada em 1596 (BOCKSTAELE, 1976).
}

RBHM, Vol. 18, nº 36, p. 77-115, 2018 
Verum miror quomodo Reverendus Pater Gruenbergerus latera invenerit polygonorum ad tabulae constructionem necessaria. Secundo miror eum ex tanto radio assumpto, devenisse tandem ad tam exiguum radium ita ut jacturam passus fuerit triginta quatuor notarum. Ego sane hoc animadverti ex constructione quam ego feci, majorem me pati non posse jacturam, quam quinque aut sex notarum.

Haec fuit quae festinanti calamo ad Reverendam Paternitatem vestram scribere volui. Vale Reverende Pater meque ut facis ama. Raptim. 1 Julij 1597 Wurceburgi.

Reverendae Paternitati vestrae addictissimus A. Romanus 
Mas admiro-me pelo modo que o Reverendo Padre Grienberger encontrou os lados dos polígonos necessários para a construção da tabela. Em segundo lugar, admiro-me de ele, a partir de um raio tomado tão grande, ter chegado ainda a um raio tão pequeno, de forma que assim a perda foi do passo das trinta e quatro casas. Eu bem percebi isso a partir da construção que eu fiz, por não poder sofrer uma perda maior do que cinco ou seis das casas.

Essas foram as coisas que com uma pena apressada quis escrever a vossa Reverenda Paternidade. Passa bem, Reverendo Padre, e me ama como fazes. Apressadamente, 1 de julho de 1597. Wurceburgo.

Dedicadíssimo a vossa Reverenda Paternidade A. van Roomen 


\section{Carta 19}

Reverende admodum in Christo Pater, scripsi nuper ad Reverendam paternitatem Vestram, nec non ad Reverendum Patrem Gruenbergerum. Neque ut iterum scriberem, responsum expectare volui, sed propter oblatam oportunitatem hasce do.

Mitto meam in Archimedis libellum analysin, una cum exercitationibus cyclicis, in quibus videbis nugas, at cum nugatoribus nugari oportuit. Interim videbis me monitioni Vestrae obtemperasse dum scriberes Ne parcas illi etc. Videbis me etiam satis ejus elatum animum depressisse. Nam vix punctulum unum omisi quod falsitatis non arguerim. Ego quid ad haec sit responsurus expectabo.

Sed audi lepidum quid. Ego de impressione conveni cum Typographo Genevensi Calviniano ut librum excuderet (Francofurtani namque me luserunt spe). Aegre tulerunt Calviniani, me Catholicum, rejicere doctrinam celeberrimi inter Calvinianos, ideo multi me fuerunt hortati ut ab incepto desisterem. At vero multo egrius tulerunt librum illum contra Calvinianum, imprimi in civitate Calvinianorum capite. Ideo inter studiosos Genevenses tumultus ortus est, libri impressionem prohibere voluerunt imo et exemplar supprimi (Ego sane aliud non habui festinanti enim calamo descripseram, neque transcribendi fuit ocium). At Typographus (uti mihi tum per ipsum tum per alios relatum fuit) suscepti operis fidelem sese praestitit patronum. Nil (uti ego eum antea informaram) in opere contineri quod concerneret religionem aut Reipublicae salutem asseruit. Liber examinatus fuit et ut asseruit Typographus ita quoque a censoribus fuit judicatum. Quare fredentibus omnibus studiosis Scaligero addictissimis, Typographus extorsit authoritatem imprimendi et excusus est imo (uti etiam cum eo conveneram) sub titulo civitatis Wurceburgensis. At vero non parum erravit Typographus in Titulo dum me professorem Matheseos hic Wurceburgi vocat cum nulla mihi hic talis sit professio sed dumtaxat Medicinae. Vocavit et Excellentissimum, quod a mea modestia solet esse alienissimum. Verum causam erroris in me conjicit quod ego simpliciter scripserim authore A. Romano. Existimavit enim eum titulum nimis esse vilem. 


\section{Carta 19}

De van Roomen em Wurceburgo para Clavius em Roma.

17 de setembro de 1597.

Padre muito reverendo em Cristo Pai, escrevi há pouco tempo para Vossa Reverenda paternidade, mas não para o Reverendo Padre Griemberger. E como não escreveria de novo, quis esperar uma resposta, mas por causa da oportunidade oferecida dou estas coisas.

Envio minha análise do pequeno tratado de Arquimedes $^{20}$, juntamente com exercícios cíclicos, nos quais verás frivolidades, mas com os frívolos foi conveniente ser frívolo. Entrementes verás que eu obedeci a seu conselho quando escreves "Não poucas eles etc."21. Verás também que eu rebaixei suficientemente o elevado ânimo dele. Pois quase não omiti nenhum ponto que eu não demonstre ser de falsidade. Esperarei o que ele haverá de responder a isso.

Mas escuta que coisa graciosa. Eu fiz um acordo de impressão com um tipógrafo calvinista genebrino para que produzisse o livro ( $\mathrm{O}$ fato é que os de Frankfurt descuidaram de minha esperança). Dificilmente os calvinistas suportaram que eu, católico, rejeitasse a doutrina do mais célebre entre os calvinistas, ponto de que muitos me tinham encorajado que desistisse desde o início. E muito mais dificilmente suportaram que aquele livro contra um calvinista fosse impresso na principal cidade dos calvinistas. Assim um tumulto surgiu entre os estudiosos de Genebra, quiseram proibir a impressão do livro e até quiseram que o original fosse suprimido (Eu certamente, de fato descrevera com uma apressada pena, e não tive o tempo necessário para reescrever). Mas o tipógrafo (como foi relatado por mim tanto por ele mesmo como por outros) da obra empreendida pôs-se à disposição do fiel contratador (como eu a ele antes informara). Defendeu que nada estava contido na obra que dissesse respeito à religião ou à saúde da república. O livro foi examinado e, como o tipógrafo defendeu, assim também fora julgado pelos censores. Por isso, tendo todos os estudiosos dedicadíssimos a Scaliger, o tipógrafo recorreu à autoridade de imprimir e produziu mesmo o livro sob o título da cidade de Wurceburgo (como também eu acordara com ele). Mas não pouco errou o tipógrafo no título quando chama a mim professor de matemática aqui em Wurceburgo, porque é nula para mim aqui tal profissão, mas somente de medicina. Chamou-me também "excelentíssimo", o que para minha modéstia costuma ser estranhíssimo. Mas ele dirige a causa do erro para mim, porque eu tinha escrito simplesmente "pelo autor A. Romanus". De fato, ele considerou que esse título é excessivamente de pouco valor.

${ }^{20}$ Aqui van Roomen se refere á sua obra In Archimedis circuli dimeniosnem e a refutação da quadratura de Scaliger.

${ }^{21}$ Deve ser uma citação de uma carta de Clavius para van Roomen.

RBHM, Vol. 18, no 36, p. 77-115, 2018 
Diversis nundinis per Brechtanum factorem Bernardi Basae transmisi aliquot libros quorum non amplius recordor. At scio fuisse Sphaeram cujusdam cum Trigonometria Petisci qui eam per me voluit Reverentiae vestrae mitti, uti et tractatum Philosophicum de quadratura circuli Jacobi Christimanni. Ultimis nundinis transmisi Ludolfi van Collen libellum Belgicum insigni doctrina refertum, quem Ludolfus per me voluit Reverentiae vestrae transmitti, voluit et se apud Reverendam Paternitatem commendari, in omnibus rebus quibus labore suo (quo potest sane plurimum) servire poterit Reverentiae vestrae, offerens suam operam. Habes in eo praeter caeteris, laterum polygonorum a triangulo usque ad figuram 80 laterum.

Tabulis $^{22}$ sinuum vestras jam longo tempore absolutas esse existimo. An vero eas particulatim edere esset inutile donec perficerentur tangentes et secantes? Interim consilium penes vos est; quid et quando faciendum nostis.

An Reverentia vestra vidit Triangulorum doctrinam Vietae? Certe ea pulchra est, neque ulterius quid perfectioni accedere possit, video. Doctrina facilis est, atque ex vulgari orta postea per Aequationes dumtaxat Algebraicas inventa, dico Algebraicas figuratas aut (ut Vieta inquit) speciosas. Ego ante quatuor aut quinque annos idem tentavi faeliciterque res successit, postea tamen ejus perfectionem intermisi. Verum jam eam habemus; Demonstratio ejus per aequationes facilis est: At demonstrationes Geometricas existimo Vietam allaturum; Et sane non omnis (ut bene Vieta) constructio concinna est, ideo praestat eas concinas ab eo expectare.

Tu sane doctus est et optime in Algebra versatus, et in politioribus, nescio an Scaligero inferior, licet autem in solutione mei problematis me carpserit, nil tamen dignum relatu protulit. Nam quod aequationes sub ea forma proposuerim, id et alij quamplurimi ante me fecerunt; proportionis voce pro ratione utuntur omnes recentiores quos legi. Idem judicium de reliquis. Dicit me ignorasse numerum terminorum secundariorum qui possunt questioni meae applicari id ipsum fateor, ei doctrinam eam debeo, suffecit mihi terminus authenta quem pro constructione tabulae chordarum inquirere studebam. Et sane Ludolfus eum invenit in partibus quarum denominatur est 10000.0000.0000.0000.0000.0000. uti videre est in problemate Apolloniaco. Ego vero eum in partibus quarum denominator est 10000.0000.0000.0000.0000.0000.0000.0000.0000.0000. Eum adjunxissem nisi expectare maluissem num forsan quispiam alius responsionem sibi quoque arrogare voluerit. Quaesitum est chorda subtensa arcui 32 minutarum sive latus figurae inscriptae 675 angulorum. Haec mihi jam scribenda occurrerunt Reverende Pater.

\footnotetext{
${ }^{22} \mathrm{O}$ correto pode ser tabulas.
} 
Na última feira, enviei através do impressor Brechtanum ${ }^{23}$ de Bernardo Bassaeus um certo número de livros dos quais não mais me recordo. Sei, porém, que havia a Esfera com a Trigonometria de um certo Pitiscus ${ }^{24}$ que consentiu que ela fosse enviada a Vossa Reverência em meu nome, bem como o tratado filosófico sobre a quadratura do círculo de Jacob Christmann. Na última feira, transmiti o pequeno livro em holandês de Ludolph van Ceulen preenchido com a distinta doutrina, que Ludolph desejou que fosse enviado através de mim a vossa Reverência, desejou também ser recomendado junto à Reverenda Paternidade, em todas as coisas nas quais ele possa servir com seu trabalho (pelo qual é possível mesmo muito) a vossa Reverência, oferecendo sua obra. Tem-se nela, além de outras coisas, os lados dos polígonos, desde o triangulo até a figura de 80 lados.

Penso que já há muito tempo que vossas tabelas de senos estão perfeitas. Mas não seria inútil publicar separadamente essas enquanto são completadas as tangentes e secantes? Enquanto isso, a decisão está convosco; o que e quando vós souberdes que deve ser feito.

Por acaso vossa reverencia viu a doutrina de Viète para os triângulos? ${ }^{25}$ Certamente ela é bela, e não vejo o que mais possa aproximar-se da perfeição. A doutrina é fácil e por outro lado a partir do começo comum, depois é obtida somente através de equações algébricas, digo, algébricas figuradas ou (como diz Viète) especiosas. Eu durante quatro ou cinco anos tentei o mesmo e a coisa felizmente avançou, contudo em seguida interrompi o acabamento dessas. Mas agora as temos. A demonstração dela por equações é fácil. Mas penso que Viéte haverá de exibir as demonstrações geométricas; e razoavelmente nem toda construção está disponível, por isso cabe esperar que se tornem disponíveis por ação dele.

Tu és bastante instruído e muito bom perito em álgebra e sei que não és inferior ao Scaliger nas mais refinadas coisas, mas ainda que me tenha censurado na solução de meu problema, não apresentou nada digno de ser relatado. Pois que eu tenha oferecido as equações sob esta forma, também isso outros muitíssimos produziram antes de mim; todos os mais recentes que eu li fazem uso da palavra da proporção para a razão. O mesmo julgamento sobre as coisas restantes. Ele diz que eu ignorei o número dos termos secundários que podem ser aplicados a minha questão, isso mesmo eu confesso, a isso devo essa teoria, substitui para mim o termo principal que eu estudava para investigar a construção da tabela de cordas. E certamente Ludolph encontrou-o nas partes das quais o denominador é $10^{24}$, como é visto no problema apoloniano. Mas eu o [encontrei] nas partes das quais o denominador é $10^{40}$. Eu o teria juntado a menos que não quisesse esperar, talvez alguém quisesse de outra forma arrogar também para si a resposta. É procurada uma corda subtendida junto a um arco de 32 minutos ou o lado da figura inscrita de 675 ângulos. Essas coisas já me ocorreram de dever ser escritas ao? Reverendo Padre.

\footnotetext{
${ }^{23}$ Segundo Bockstaele (1976), não temos informações sobre o livreiro citado. Sabemos somente que existiram alguns livreiros com este sobrenome.

${ }^{24}$ Van Roomen se refere á Bartholomeu Pitiscus (1561-1613).

${ }^{25}$ Segundo Bockstaele, van Roomen se refere ao capítulo XIX da Variorum de rebus mathematicis responsorum Liber VIII de 1593.
}

RBHM, Vol. 18, no 36, p. 77-115, 2018 
Ex nundinis si quid intellexero novi de Scaligero perscribam. Utinam esset mihi occasio Italiam inhabitandi. Ego omnes vires meas intenderem, ut Reverentiam vestram in laboribus suis juvarem. Nam in calculo potissimum me expeditum libere assero et certum. Miraretur aliquando radicum extractiones, videret unam extractionem nonnumquam requirere octo vel novem folia chartae, dum ex numeris quadringentarum literarum et plurium extraho radices quadratas vel cubicas vel alias. Si in Italia alicubi professio vacaret Mathematica, ego libenter eam amplecterer. Vale Reverende Pater, meque ama et Reverendum Patrem Gruenberum ex me saluta. Wurceburgi 1597, die 17 Septembris.

Reverendae Paternitati vestrae addictissimus Adrianus Romanus

Audi lepidum judicium Scaligeri de tua castigatione Calendarij. Inquit Scaliger, Stilus libri non est Clavij. Relicta mathesi jam stilum examinat.

Vieta in octava responsorum prebet occasionem disputandi de angulo corniculari. Nam est in sententia Peletarij.

Item, de quadratura paraboles.

Interim quid de convenientia Archimedis et Euclidis sentias velim tribus verbis mihi significes. Sentit enim Vieta secundum Euclidem angulum cornicularem esse quantitatem, at secundum Archimedem non esse.

Nescio quis rumor spargatur hic de Antonio Magino, eum causa inquisitionis detineri Romae. Ego vices ejus doleo si ita sit. Suspicor forsan ob Astrologiae isagoge.

Unum ex tribus hisce exemplaribus Problematis Apolloniaci, velim dari Domino Theodosio Rubeo.

Iterum vale. 
A partir da feira se algo eu souber de novo sobre o Scaliger escreverei por completo. Quem me dera existisse para mim uma oportunidade de morar na Itália. Eu reforçaria as minhas coisas para todos os homens, para ser útil a Vossa Reverência em seus trabalhos. Pois no cálculo defendo que sou livremente muito desembaraçado e certo. Admirar-se-ia às vezes com as extrações de raízes, veria uma extração às vezes requerer oito ou nove folhas de papel, enquanto extraio raízes quadradas ou cúbicas ou outras a partir de números de quarenta casas e mais. Se em algum lugar na Itália um cargo matemático ficar vago, eu voluntariamente o abraçaria. Que passe bem, Reverendo Padre, e ama a mim e saúda por mim o Reverendo Padre Grienberger. Wurceburgo, no dia 17 de setembro de 1597.

Dedicado à vossa Reverenda Paternidade Adriaan van Roomen

Escuta um julgamento encantador de Scaliger sobre a sua [obra] Castigatione Calendarij. Diz Scaliger: "O estilo do livro não é de Clavius". Ela abandonada a matemática, examina agora o estilo.

Viéte nos oito livros do Responsorum ${ }^{26}$ aproveita a ocasião de discutir sobre o ângulo cornicular. Pois está na opinião de Peletier.

Igualmente, sobre a quadratura das parábolas.

Nesse tempo o que pensas sobre a conveniência de Arquimedes e Euclides quereria que em três palavras me mostre. Viète de fato pensa segundo Euclides que o ângulo cornicular é uma quantidade, mas segundo Arquimedes não é.

Não sei quem dissemina aqui um rumor sobre Antonio Magini, de ele estar detido em Roma por causa da inquisição. Eu lamento por ele se assim for. Suspeito que por ventura seja por causa da Introdução à Astrologia.

Um desses três exemplares do Problema Apoloniano queria que fosse dado ao Senhor Theodosius Rubeus.

Pela segunda vez, passa bem.

${ }^{26}$ Aqui a obra Variorum de rebus mathematicis responsorum Liber VIII novamente é mencionada.

RBHM, Vol. 18, no 36, p. 77-115, 2018 